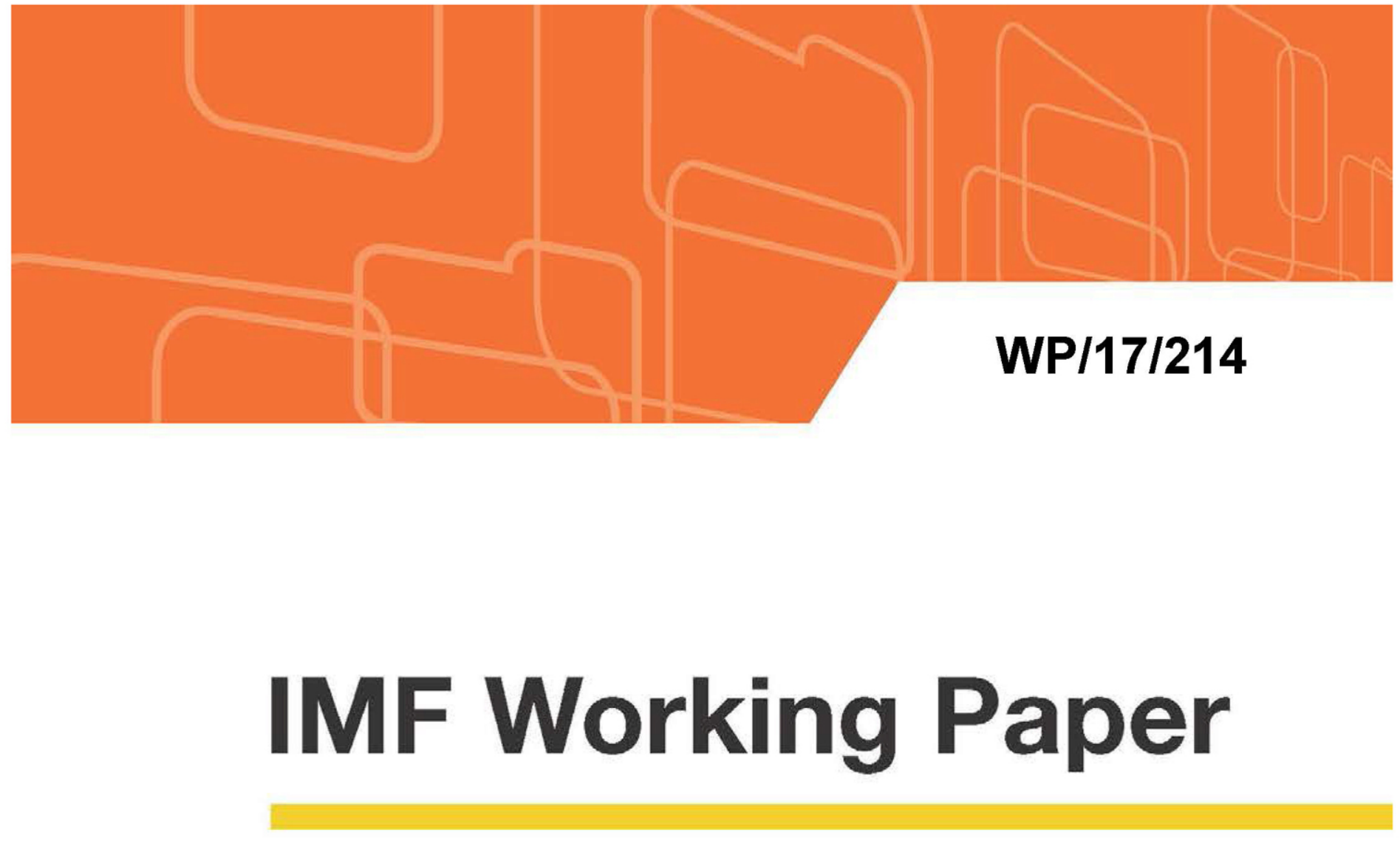

\title{
Lessons from the Old Masters on Assessing Equity and Efficiency: A Primer for Fiscal Policymakers
}

by Vitor Gaspar, Paolo Mauro, and Tigran Poghosyan

IMF Working Papers describe research in progress by the author(s) and are published to elicit comments and to encourage debate. The views expressed in IMF Working Papers are those of the author(s) and do not necessarily represent the views of the IMF, its Executive Board, or IMF management. 


\section{WP/17/214}

\section{IMF Working Paper}

\section{Lessons from the Old Masters on Assessing Equity and Efficiency: A Primer for Fiscal Policymakers}

by Vitor Gaspar, Paolo Mauro, and Tigran Poghosyan

IMF Working Papers describe research in progress by the author(s) and are published to elicit comments and to encourage debate. The views expressed in IMF Working Papers are those of the author(s) and do not necessarily represent the views of the IMF, its Executive Board, or IMF management.

I N T E R N A T I O N A L M O N E T A R Y F U N D 


\title{
IMF Working Paper
}

Fiscal Affairs Department

\section{Lessons from the Old Masters on Assessing Equity and Efficiency:}

\author{
A Primer for Fiscal Policymakers \\ Prepared by Vitor Gaspar, Paolo Mauro, and Tigran Poghosyan ${ }^{1}$
}

October 2017

\section{IMF Working Papers describe research in progress by the author(s) and are published to elicit comments and to encourage debate. The views expressed in IMF Working Papers are those of the author(s) and do not necessarily represent the views of the IMF, its Executive Board, or IMF management.}

\begin{abstract}
How can a society's well-being be measured to include not only average incomes but also their distribution? How can the effects of policies be assessed by considering both equity and efficiency? This primer outlines the seminal contributions of influential economists of the past, including Arthur Okun, who developed a simple method to elicit people's preferences regarding redistribution, and Anthony Atkinson, who showed how equity and efficiency can be measured simultaneously and summarized in a single, intuitive index expressed in monetary units (such as dollars). These methods are applied to recent data to gauge how countries fare when both mean incomes and their distribution are considered together, and to a hypothetical tax-and-transfer scheme assessed through a general equilibrium model for household-level data.
\end{abstract}

JEL Classification Numbers: I3, D62, H2

Keywords: equality and efficiency, fiscal redistribution

Authors’ E-Mail Addresses: vgaspar@imf.org, pmauro@imf.org, tpoghosyan@imf.org.

\footnotetext{
${ }^{1}$ We would like to thank Dave Coady, Mercedes Garcia-Escribano, Aart Kraay, Hiroaki Miyamoto, and especially Adrian Peralta-Alva and Philippe Wingender, as well as many other IMF colleagues and participants in the plenary session on "Inequality and the Distributional Impact of Macroeconomic Policies" at the Annual Congress of the European Economic Association (Lisbon, August 22, 2017) for useful comments and suggestions. We are grateful to Adrian Peralta-Alva for providing model simulations. Saida Khamidova provided excellent research assistance.
} 


\section{Content}

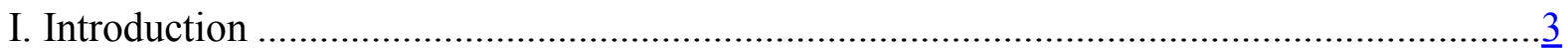

II. The "Old Masters" on Assessing Equity and Efficiency ….............................................

A. Eliciting Observers' Aversion to Inequality: Okun's "Leaky Bucket” Exercise....... 4

B. Eliciting Observers' Aversion to Inequality: Functional Forms ............................. $\overline{5}$

C. Summarizing Society's Welfare: Equally-Distributed-Equivalent Incomes .............

D. Relationship between Okun's Leaky Bucket Exercise and Atkinson's Equally-

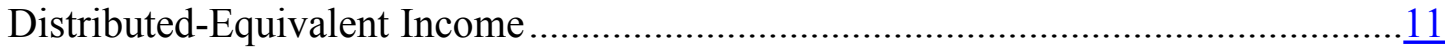

E. Links to Related Studies ...........................................................................

III. Empirical Applications ................................................................................... 14

A. Average Incomes and Distribution for a Large Panel of Countries .......................14

B. Assessment of Policies_-Example: A Tax-and-Transfer Scheme ..........................17

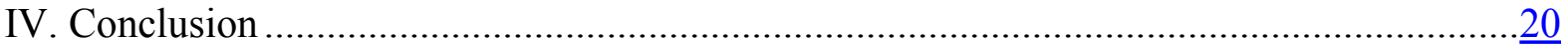

Tables

1. Maximum Acceptable Leakage, Inequality Aversion, and Ratio of Incomes ...................... $\underline{6}$

2. EDEI and Coefficient of Inequality Aversion ............................................................. $\frac{11}{16}$

3. Equally-Distributed-Equivalent Income for Different Inequality Aversion, $2015 \ldots \ldots \ldots \ldots \ldots . .16$

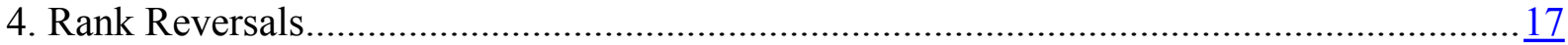

Figures

1. Social Welfare and Income Inequality....................................................................... 8

2. Equally-Distributed-Equivalent Income and Aversion to Inequality ............................. $\frac{10}{12}$

3. Relationship Between the Size of the Transfer and the Coefficient of Inequality............... 12

4. Mean Incomes and Equally-Distributed-Equivalent Incomes (in logarithms) ................... 16

5. Changes in Social Welfare and Its Components Over 2003-15 (in logs) .......................... $\frac{18}{20}$

6. Gains in EDEI from the Introduction of UBI for Different Financing Sources ................. $\underline{20}$

Boxes

1. Income Distribution - Data from Household Surveys................................................... 14

2. Dynamic Stochastic General Equilibrium Model Used to Analyze the Potential Introduction of a Universal Basic Income .....................................................................................

Appendices

A. Deriving the Social Welfare Function (SWF) ........................................................... 22

B. Relating Atkinson's Inequality Index to Okun's Leaky Bucket ...................................... 25

C. Relating Okun's Leaky Bucket Exercise to Optimal Income Taxation ............................. 27

Appendix Table

1. Comparison of Country Ranks Based on Mean Income and Social Welfare (EDEI) ..........29

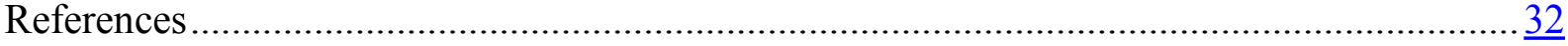


Economic welfare is liable to be affected in an important degree (1) through the size of the national dividend and (2) through the way in which it is distributed among the members of the community—A. C. Pigou, 1920.

\section{INTRODUCTION}

Public discourse on inequality has become more prominent in recent years, rekindling interest in methods to assess the implications of policies not only for total economic output but also for its distribution. Against this background, it is worth re-emphasizing some lessons from the "old masters" in economics who addressed this topic a few decades ago-including Arthur M. Okun and Anthony B. Atkinson in the 1970s. Their lessons - on how to elicit people's views on inequality and how to summarize societal welfare using a monetary indicator encompassing both average incomes and their distribution-remain relevant for fiscal policymakers today. As emphasized by Pigou (1920) in the quote above and De Graaff (1957), a satisfactory theory of welfare must recognize that welfare depends on both the size and the distribution of national income. Indeed, an intuitively appealing, single indicator combining both efficiency and equity considerations may be used not only to gauge the wellbeing of countries but also to rank different policies. This primer summarizes the old masters' contributions and applies them to recent data on income distribution for a large sample of countries.

Although the theory of welfare is a mature, well-developed field in academia, its practical application is not commensurately frequent or systematic. This primer seeks to encourage more widespread use by policymakers of the tools developed by welfare theory. Rather than attempting a comprehensive review of the plethora of methods to elicit people's attitudes toward income redistribution and to conduct analysis based on social welfare functions, the primer provides an in-depth, step-by-step refresher on two specific tools chosen because of their simplicity and intuitive appeal: Okun's "leaky bucket" and Atkinson's "equallydistributed-equivalent income." By doing so, it illustrates both the potential benefits of systematic welfare analysis and the types of assumptions needed to undertake it.

The next section outlines a few seminal contributions by influential economists of the past to the analytical methods for the joint assessment of equality and efficiency. Section III presents empirical illustrations based on recent data for a panel of countries and calibration of the impact of a hypothetical tax-and-transfer scheme in a general equilibrium setup. The last section concludes.

\section{The "Old Masters" on Assessing EQuity AND EfFiciency}

A joint assessment of equity and efficiency requires a method to elicit people's views on the relative importance of these two aspects of well-being, and a way of putting the two together into a single measure. 
Economic welfare is best promoted by a minimum standard raised to such a level that the direct good resulting from [..] the marginal pound transferred to the poor just balances the indirect evil brought about by the consequent reduction of the [national] dividend-A. C. Pigou, 1920.

\section{A. Eliciting Observers' Aversion to Inequality: Okun's "Leaky Bucket" Exercise}

To devise a measure combining both total income in an economy and its distribution across households, a necessary first step is to establish the relative weights of those two components. To that end, Okun (1975) proposed a thought experiment capable of eliciting people's attitudes toward the trade-off between equality and efficiency: Okun asked the reader to consider five families: a richer one making $\$ 45,000$ (in 1975) and four poorer ones making $\$ 5,000$. Would the reader favor a scheme that taxed the rich family $\$ 4,000$ and transferred the proceeds to the poorer families? In principle, each poorer family would receive $\$ 1,000$. But what if 10 percent leaked out, with only $\$ 900$ reaching the recipients? What would the maximum acceptable leak be? ${ }^{2}$

The leak represented not only the administrative costs of tax-and-transfer programs (and, one might add, potential losses due to corruption), ${ }^{3}$ but also the fact that such programs reduce the economic incentives to work. ${ }^{4}$

To simplify, assume that there are only two families, denoting initial income levels $I_{P}$ for the poor family and $I_{R}$ for the rich family. The proposed tax-and-transfer schemes would result in income $I_{P}+(1-b) T$ for the poor family and $I_{R}-T$ for the rich family, where $b$ is the percent of the transfer paid by the rich that fails to reach the poor $(0 \leq b \leq 1)$. Assume that observers care equally about the two families' incomes, through a function $w(I) .{ }^{5}$ Observers will then agree to the scheme if:

$$
w\left(I_{P}+(1-b) T\right)+w\left(I_{R}-T\right) \geq w\left(I_{P}\right)+w\left(I_{R}\right)
$$

In the case of a tax-and-transfer scheme involving very small transfers (i.e., "marginal" transfers in economists' parlance), the scheme will be desirable if

$$
(1-b) w^{\prime}\left(I_{P}\right) \geq w^{\prime}\left(I_{R}\right)
$$

\footnotetext{
${ }^{2}$ According to the Dalton-Pigou principle (see Dalton, 1920 and Pigou, 1912), any transfer from the rich to the poor reduces inequality (as long as it does not bring the rich to a poorer situation than the poor). Okun makes the exercise more interesting by introducing an inefficiency (the leak) in the transfer process.

${ }^{3}$ Okun described the leak as a "technological problem." Recent technological improvements, such as biometric identity cards, make it easier to effect transfers to the right individuals, even in developing countries, with more limited leakages than in the past.

${ }^{4}$ Okun's analysis considers only contemporaneous effects on output: it ignores any potential impact on economic growth of lower incentives to invest in education, physical capital, research and development, or entrepreneurial activity.

${ }^{5}$ The assumption that external observers care about households' incomes, rather than consumption, facilitates the analysis by obviating the need to consider savings, choices of consumption across different goods and services, and prices of goods and services.
} 
Although Okun reported his own answers to the specific exercise he proposed (his personal preference was for a leakage of no more than 60 percent), a method to extract observers' aversion to inequality in a more systematic manner would require further assumptions about the shape of such preferences.

\section{B. Eliciting Observers' Aversion to Inequality: Functional Forms}

Atkinson (1970) showed that the analysis of income inequality is easier if it is assumed that observers assess the well-being of a given household using a function of the following form:

$$
w(I)=\frac{I^{1-\varepsilon}}{1-\varepsilon}
$$

Where $I$ is disposable income and $\varepsilon$ is the coefficient representing aversion to inequality. ${ }^{6}$ This functional form can be derived using minimal assumptions - additive separability and homotheticity-regarding the social welfare function (Appendix A). With this function, aversion to inequality depends only on income distribution: proportional increases to each household's income would have no effect on an observer's view of society's well-being beyond the impact of the rise in average income.

Applying the functional form in (3) to Okun's original exercise and to his specified maximum acceptable leakage, it is possible to derive Okun's own personal preferences. He stated that he would have been indifferent between the following:

$$
\frac{(45,000)^{1-\varepsilon}}{1-\varepsilon}+4 \frac{(5,000)^{1-\varepsilon}}{1-\varepsilon}=\frac{(41,000)^{1-\varepsilon}}{1-\varepsilon}+4 \frac{(5,400)^{1-\varepsilon}}{1-\varepsilon}
$$

(Recall, in fact, that Okun was willing to accept that a $\$ 4,000$ tax on the rich household translate, with a 60 percent leakage, into a $\$ 400$ transfer to each of the four poor households.) Solving equation (4) yields Okun's personal coefficient of aversion to inequality as $\varepsilon=0.4338$.

A computationally easier way to elicit an observer's aversion to inequality is to propose a taxand-transfer scheme involving very small possible amounts. Applying (2) to the functional form above, additional transfers from the rich to the poor will be desirable up to the point where:

$$
\left(\frac{I_{R}}{I_{P}}\right)^{\varepsilon}=\frac{1}{1-b}
$$

\footnotetext{
${ }^{6}$ This is the same form as a constant relative risk aversion utility function. In the special case of inequality aversion equal to 1 , the functional form is $w(I)=\log (I)$. It would be inappropriate, however, to use estimated coefficients of risk aversion to assess aversion to inequality.
} 
(Applied to Okun's exercise, where the ratio of incomes of the rich to those of the poor equals 9 and the leakage coefficient equals 0.6 , this yields $\varepsilon=0.42$, a good approximation. See Blinder, 1982.)

Hence, when observers are presented with an assumption about the leakage coefficient and are given choices over whether a given transfer from the rich family to the poor family is desirable, it is possible to infer their coefficient of aversion to inequality, $\varepsilon$. Conversely, if one is willing to assume a value for $\varepsilon$, then observers' responses will reveal how much leakage they are willing to accept (the maximum $b$ ). Combinations of inequality aversion and maximum leakage such that equality (5) holds are reported, for various possible ratios of the incomes of the rich to the incomes of the poor, in Table 1.

Table 1. Maximum Acceptable Leakage, Inequality Aversion, and Ratio of Incomes

\begin{tabular}{|c|c|c|c|c|c|c|}
\hline$\varepsilon$ & $I_{R} / I_{P} \quad 2$ & 3 & 4 & 5 & 10 & 25 \\
\hline 0.2 & 0.13 & 0.20 & 0.24 & 0.28 & 0.37 & 0.47 \\
\hline 0.5 & 0.29 & 0.42 & 0.50 & 0.55 & 0.68 & 0.80 \\
\hline 1.5 & 0.65 & 0.81 & 0.88 & 0.91 & 0.97 & 0.99 \\
\hline 2.0 & 0.75 & 0.89 & 0.94 & 0.96 & 0.99 & 0.998 \\
\hline
\end{tabular}

Note: The table reports the maximum acceptable share of the amount transferred from the rich household that leaks out before reaching the poor household. $I_{R} / I_{P}$ is the initial income of the rich household divided by the initial income of the poor household. The coefficient of aversion to inequality is $\varepsilon$.

Several studies (e.g., Amiel and Cowell 1999; Pirttila and Uusitalo 2010) have elicited attitudes toward inequality, usually finding $\varepsilon$ in the range of $0.2-2.0$. For instance, Pirttila and Uusitalo (2010) surveyed a random sample of 3000 Finnish adults, split into four subgroups of 750. Each subgroup received a questionnaire asking respondents whether they would support a transfer from the top income decile earners ( $>€ 3300$ per month) to the bottom decile earners ( $<€ 800$ per month). Each questionnaire had different leakage: $b=0.5,0.75,0.94$, and 0.985 , corresponding to inequality aversion $\varepsilon=0.5,1.0,2.0$, and 3.0, respectively-see (5).

Respondents could answer "yes", "no", or "cannot say" to the transfer. As expected, support for the transfer decreased with higher leakage. But even with the lowest aversion to inequality and least leakage ( $\varepsilon=0.5, b=50 \%$ ), less than 30 percent of respondents were in favor of the transfer. This suggests that the median inequality aversion of the respondents lies below 0.5 . Even so, more than 20 percent of respondents were in favor of the transfer for a leakage coefficient corresponding to inequality aversion as high as 3 .

Harberger (1983) combines Okun's leaky bucket experiment with Atkinson's social welfare function to argue that aversion to inequality in the U.S. is relatively low. Using the ratio of average incomes of top and bottom deciles (nine-to-one) and setting the coefficient of inequality aversion to 0.5 , he estimates the ratio of marginal effects to be three-to-one from (5). This implies that society believes that an additional dollar of income is worth three times as much to the poorest people than to the richest people, yet it stops redistributing it at a point 
at which the disparity in incomes between the richest and the poorest is much larger. Therefore, the coefficient of inequality aversion accepted by the society must be less than 0.5 .

Hendren (2013) analyzes the case of earned income tax credit (EITC) expansions and the top marginal income tax schedule in the U.S. Per his estimates, additional redistribution from rich households earning above $\$ 400,000$ to EITC beneficiaries is desirable for the leakage coefficient ranging between 34-56 percent. This contrasts with Harberger (1983), who thought that the leak should be much lower given that at that time the best estimates of the marginal dead weight loss from income taxes were on the order of 10 cents per dollar and administrative and compliance costs were assumed to be small.

Using approaches other than the leaky bucket exercise often leads to significantly higher estimates of the inequality aversion coefficient. For example, when Pirttila and Uusitalo (2010) presented their same sample of respondents with various hypothetical income distributions, most respondents chose the least unequal distribution, leading to a median estimate of the inequality aversion coefficient of three or above. A study by Bargain and others (2014) sought to measure revealed aversion to inequality for 17 European countries and the United States by analyzing the degree of redistribution implicit in their tax-and-benefit systems, while controlling for different elasticities of labor supply. It found inequality aversion below one for most Southern European countries and the United States, around one for Continental Europe, the United Kingdom, Ireland and Finland, and ranging between one and three for Belgium and the Scandinavian countries. The reasons why different approaches yield different coefficients are not fully understood, but may have to do with respondents' inconsistencies across different exercises, political systems' inability to deliver policies in line with citizens' preferences, or overly stringent assumptions regarding the shape of the social welfare function.

\section{Summarizing Society's Welfare: Equally-Distributed-Equivalent Incomes}

The one obvious instrument of measurement available in social life [for economic welfare] is money_A. C. Pigou, The Economics of Welfare, 1920.

Atkinson (1970) showed that under the assumptions above and having identified a coefficient of aversion to inequality, it becomes easy to summarize the well-being of all households in an economy with a single, intuitive measure: the equally-distributed-equivalent income (EDEI), i.e., the income that an external observer would consider just as desirable as the existing income distribution. Part of the appeal of EDEI is that it is measured in dollars. ${ }^{7}$

To illustrate for the case of two families, consider the initial situation of $I_{P}$ for the poor family and $I_{R}$ for the rich family and ask: if one were to increase $I_{P}$ and to lower $I_{R}$, what is the

\footnotetext{
${ }^{7}$ The concept of EDEI can be based upon various social welfare functions — not just the one considered here.
} 
equally distributed income that would be just as desirable as the current situation, from the standpoint of an external observer?

Aversion to inequality may be represented by lower and lower increases in the value an observer places on an additional dollar given to a household, as such household becomes richer. Figure 1 does so by plotting a function $w(I)$ representing the contribution to societal well-being of the incomes of the poor and the rich households, $w\left(I_{P}\right)$ and $w\left(I_{R}\right)$, respectively. The more concave is the function the higher is inequality aversion. If $w(I)$ were linear, the observer would be indifferent to whether an extra dollar accrues to the poor or the rich, and would thus place no value on reducing inequality.

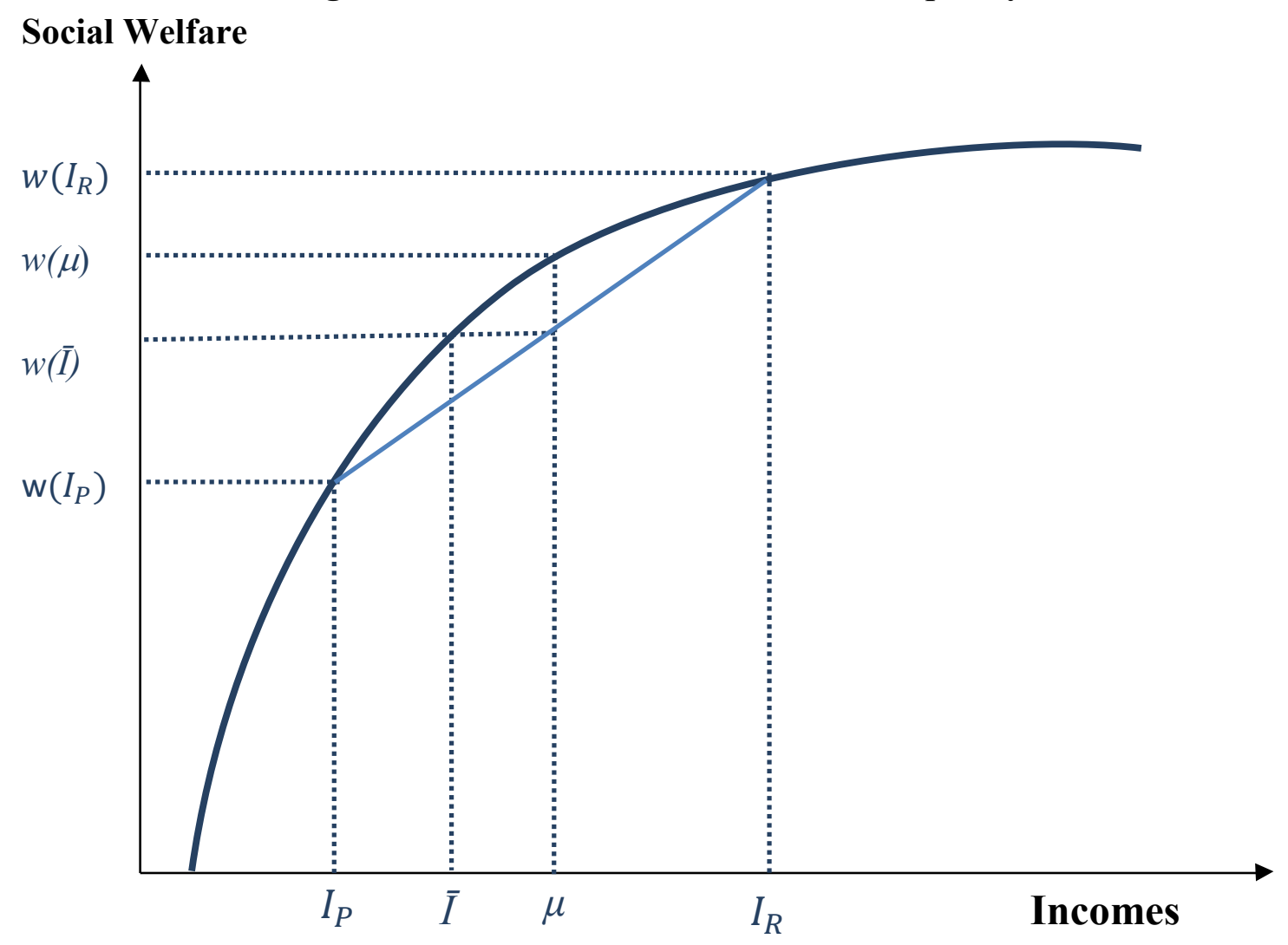

Note: $I_{P}$ is the income of a poor household, $I_{R}$ is the income of a rich household, $\mu=\left(I_{P}+I_{R}\right) / 2$ is average income in the initial situation, and $\bar{I}$ is the equally distributed equivalent income.

By definition of concavity, $w(\mu)>(1 / 2)\left[w\left(I_{P}\right)+w\left(I_{R}\right)\right]$. Thus, the observer can identify an equally-distributed level of income, $\bar{I}$, lower than $\mu$, such that average well-being can be preserved as equal to $(1 / 2)\left[w\left(I_{P}\right)+w\left(I_{R}\right)\right]$. At such equally-distributed-equivalent income (EDEI), the following holds:

$$
2 * w(\bar{I})=w\left(I_{P}\right)+w\left(I_{R}\right)
$$


Society can achieve the same overall well-being as in the initial situation by equalizing incomes at level $\bar{I}$, even if that entails a loss in average income compared with initial mean income $\mu$. The gap between $\mu$ and $\bar{I}$ is greater the more averse to inequality is the observer and the larger is the distance between $I_{P}$ and $I_{R}$.

The percentage loss in mean income - compared with the initial situation - that an observer would find acceptable to have a perfectly equal distribution of incomes was introduced by Atkinson (1970) as a measure of inequality. Atkinson's inequality index, $A$, is defined as:

$$
A=\frac{\mu-\bar{I}}{\mu}=1-\frac{\bar{I}}{\mu}
$$

where $\mu$ is mean income and $\bar{I}$ is the EDEI. If $\bar{I}$ is, say, 80 percent of mean income, the observer would be willing to give up 20 percent of total societal income in exchange for equally distributed income at level $\bar{I}$. (The index varies between 0 , perfect equality to begin with, and 1, a most unequal initial distribution.)

In the case of many households $(j=1, . . n)$, the EDEI is obtained from:

$$
w(\bar{I})=\frac{1}{n} \sum_{j=1}^{n} w\left(I_{j}\right)
$$

The concept of EDEI and Atkinson's measure of inequality may be illustrated further by measuring the incomes of the two households on each of the graph's axes (Figure 2).

Point $\mathrm{K}$ represents the initial income distribution, with households 1 and 2 endowed with $I_{P}$ and $I_{R}$, respectively. Point K' simply reverses the distribution of incomes. The straight line KEK' consists of points with the same total (mean) income as in K and K'. The curve KCK' represents all combinations of incomes that, from the viewpoint of an external observer, preserve total well-being the same as in the initial situation. K' lies on that indifference curve because incomes are the households' only feature relevant to the observer. Indeed, KCK' is symmetric across the $45^{\circ}$ line. As the additional value of an extra dollar is lower and lower as a household's income rises, KCK' has a convex shape. Point $C$ represents the situation in which both households earn the equally-distributed-equivalent income, $\bar{I}$. Again, $\bar{I}$ is lower than $\mu$, the average of $I_{R}$ and $I_{P}$. The gap between $\mu$ and $\bar{I}$ is larger the more convex is the

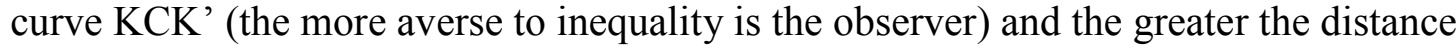
between $I_{R}$ and $I_{P}$ in the first place. Again, Atkinson's index of inequality is $A=1-\bar{I} / \mu$.

Also reported are two extreme cases for the curvature of $\mathrm{KCK}^{\prime}$. If that were linear, the observer would be indifferent regarding the distribution of income across households ("utilitarian" case). Inequality aversion would be zero and the only relevant consideration would be total (mean) income. At the opposite extreme, social well-being would be assessed solely based on the income of the poorer household ("Rawlsian" case). This is equivalent to infinite inequality aversion. 
Turning to a numerical example, consider again the situation where $I_{R}=\$ 45,000$ for the rich family and $I_{P}=\$ 5,000$ for the poor family. An external observer would assess the EDEI, labeled $\bar{I}$, as the equally-distributed income level yielding the same total well-being as in the initial situation:

$$
2 * w(\bar{I})=w\left(I_{P}\right)+w\left(I_{R}\right)
$$

Figure 2. Equally-Distributed-Equivalent Income and Aversion to Inequality

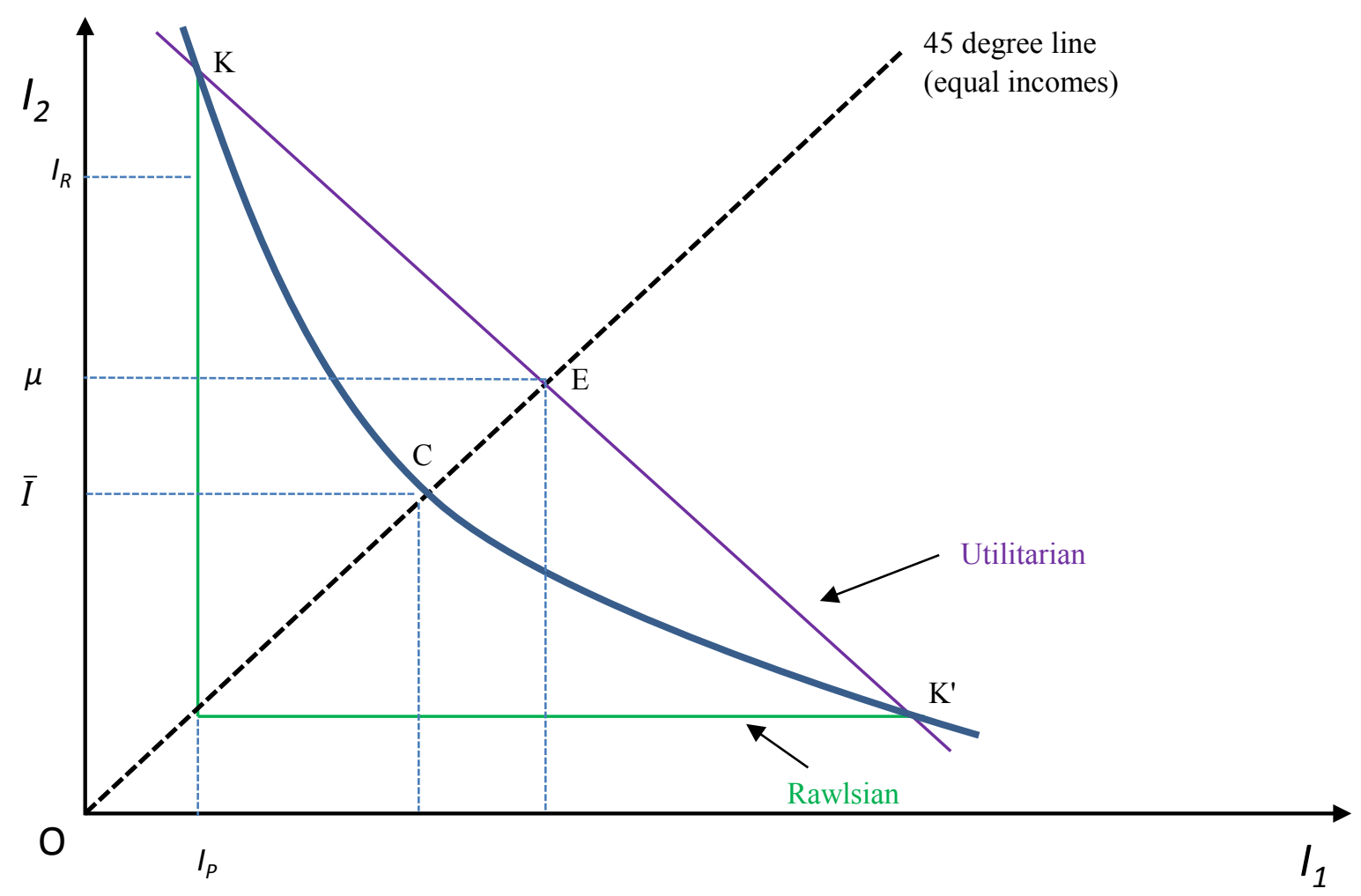

Note: $I_{I}$ and $I_{2}$ denote the incomes of households 1 and 2, respectively. In the initial situation, $I_{I}=I_{P}$ and $I_{2}=I_{R}$. Mean income is $\mu=(1 / 2)\left(I_{P}+I_{R}\right)$. The external observer considers $I_{I}=I_{2}=\bar{I}$ to be just as desirable as the initial situation.

Using the functional form reported above (constant relative inequality aversion) and assuming $\varepsilon=0.5$, the EDEI would be $\$ 20,000$. In this case, the total initial income was $\$ 50,000$, and the total income after equalization is $\$ 40,000$. From the external observer's perspective, a loss of 20 percent in total income would be acceptable if it rendered the families' incomes the same. (If such income equalization were accomplished through a tax-and-transfer scheme, this would involve - using Okun's terminology - a 40 percent leakage: the rich family is taxed $\$ 25,000$, but the poor family only receives a transfer of $\$ 15,000$. Of course, the external observer would choose to undertake the tax-and-transfer scheme only if its technology involved a leakage coefficient of no more than 40 percent.)

The greater the observers' aversion to inequality, the lower the EDEI. Table (2) reports $\bar{I}$ for a few alternative $\varepsilon$ coefficients, for the example above. 
Table 2. EDEI and Coefficient of Inequality Aversion

\begin{tabular}{|c|c|c|c|c|c|}
\hline$\varepsilon$ & 0.2 & 0.5 & 0.9 & 1.5 & 2.0 \\
\hline $\bar{I}$ & 23,084 & 20,000 & 15,931 & 11,250 & 9,000 \\
\hline
\end{tabular}

\section{Relationship between Okun's Leaky Bucket Exercise and Atkinson's Equally- Distributed-Equivalent Income}

The exercises by Okun, to consider potential tax-and-transfers schemes with a leaky bucket, and by Atkinson, to compute an EDEI, are distinct, but related.

Okun's exercises ask observers to consider tax-and-transfer schemes, typically on a smaller scale that does not necessarily equalize incomes: each such exercise asks observers whether, for a given leakage coefficient, a tax-and-transfer scheme is acceptable.

Atkinson's exercise to calculate the EDEI only requires knowing the external observer's coefficient of aversion to inequality. No assumptions about leakage coefficients are required to complete that exercise. Even so, having estimated the EDEI, one can infer the leakage that would be associated with a tax-and-transfer scheme to move from the initial situation to perfect equality. The external observer would only decide to render incomes equal by undertaking the tax-and-transfer scheme if it were technically feasible with an acceptably low leakage. If the observer were asked about whether she would want to proceed with the taxand-transfer scheme to equalize incomes, then Atkinson's exercise would become a special case of Okun's leaky bucket exercise.

Appendix B derives the relationship between Atkinson's index of inequality (i.e., the percentage loss in total income that an observer would find acceptable to equalize incomes), the size of the transfer that needs to be made from the rich to the poor to equalize incomes, the leakiness of the bucket, and the observer's aversion to inequality, $\varepsilon$.

Returning to the case of $I_{R}=\$ 45,000$ and $I_{P}=\$ 5,000$, assuming again that the leakage coefficient is 0.6 (regardless of the size of the transfer), it is instructive to ask what coefficient of aversion to inequality is necessary to make transfers of different magnitudes acceptable. In each of these exercises, the starting point is always the same $\left(I_{R}=\$ 45,000 ; I_{P}=\$ 5,000\right)$ and the transfer under consideration is an indivisible lump sum: either transfer the whole amount or nothing.

As shown above, the observer would agree to a small transfer (say, $\$ 1-100$ ), if $\varepsilon \geq 0.42$, and to a (gross) transfer of $\$ 1,000$ from the rich if $\varepsilon \geq 0.43$. Larger transfers would only be acceptable if aversion to inequality were larger. The minimum required $\varepsilon$ is to be found by solving (5) for $\varepsilon$. The reason for the rise in requisite $\varepsilon$ is that with larger transfers, the gap between the incomes of the poor and the rich becomes smaller and thus the benefit-from the external 
observer's viewpoint - of each additional dollar transferred also declines. The largest possible transfer in this example is the transfer that equalizes incomes after considering the 60 percent leakage. The amount is obtained by solving the following equation for $\mathrm{T}$ :

$$
I_{R}-T=I_{P}+(1-b) T
$$

For $I_{R}=\$ 45,000, I_{P}=\$ 5,000$, and $b=0.6$, the solution is $T=\$ 28,571$.

As reported in the Figure 3, larger transfers require a higher coefficient of aversion to inequality to be acceptable.

Figure 3. Relationship Between the Size of the Transfer and the Coefficient of Inequality Aversion (leakage $=60 \%$ )

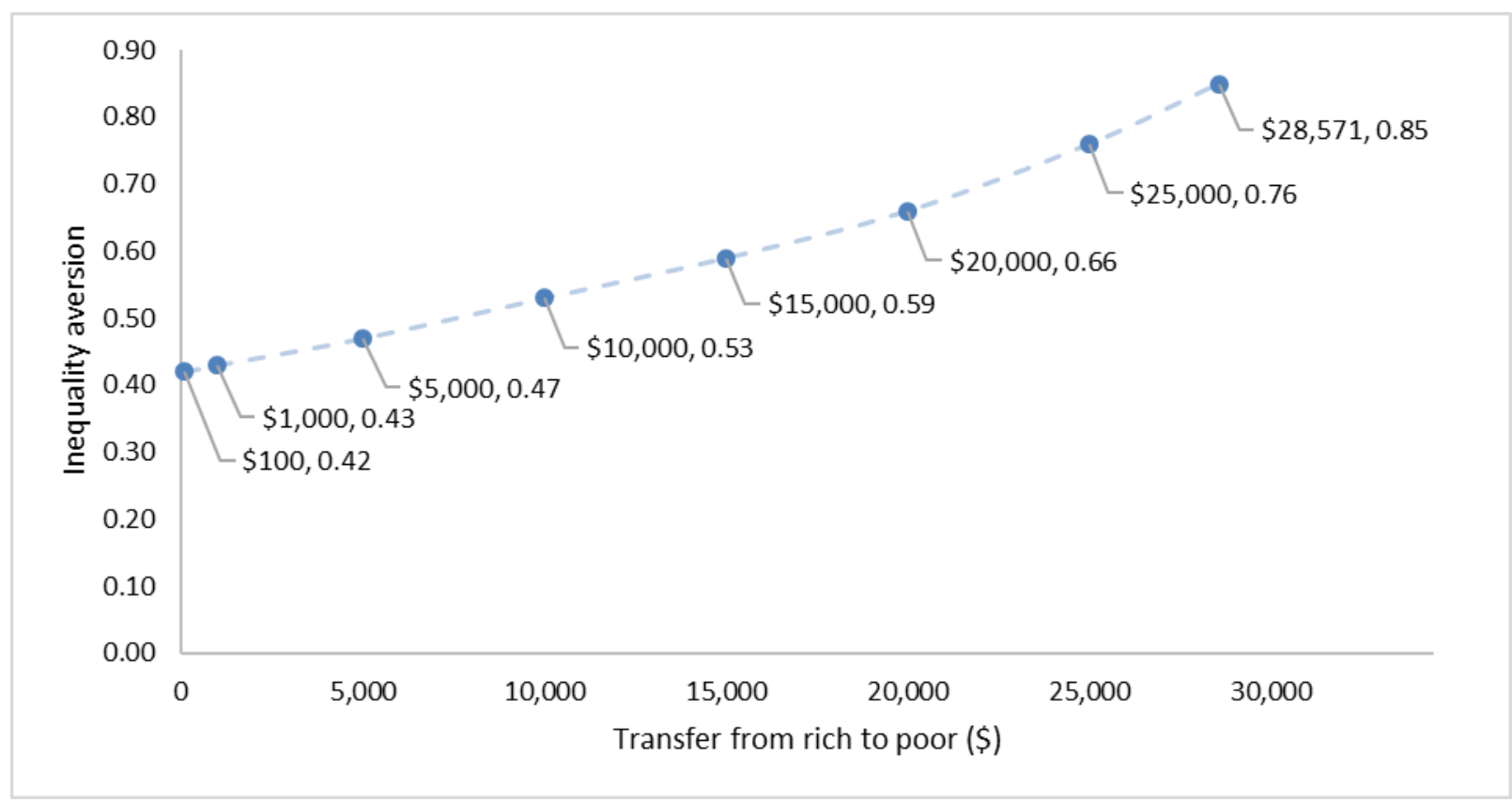

Note: Assuming initial incomes of $\$ 45,000$ for the rich and $\$ 5,000$ for the poor.

\section{E. Links to Related Studies}

It is also instructive to relate the exercises above to a few important strands of research on public finance, income distribution, and economic growth, including: (i) the debate on whether there is a tradeoff between income redistribution and economic growth; (ii) other measures of social welfare that combine equity and efficiency considerations; and (iii) optimum income taxation.

\section{Tradeoffs between efficiency and redistribution?}

Although Okun's leaky bucket exercise is based upon the premise that redistribution causes a loss in total income at a given point in time, using the exercise is compatible with the view 
that there is no clear relationship (or that there may well be a negative relationship) between inequality and economic growth (as argued, for example, by Ostry, Berg, and Tsangarides, 2014).

If the bucket were not leaky, an external observer would equalize incomes, regardless of the coefficient of inequality aversion. Thus, the existence of a tradeoff between efficiency and equality, represented by a positive leak, is inherent in the exercise. Even so, the purpose of the exercise is to elicit people's preferences about redistribution. Any such preferences are compatible with the possibility that statistical analysis is unable to uncover any empirical regularities between redistribution and economic growth. In practice, some inequality is integral to the effective functioning of a market economy, and to providing incentives for investment and growth. But excessive inequality can also be detrimental to growth, for example, by making it difficult for the poor to invest in education or health care, or by creating the risk of political upheaval.

\section{Other measures of social welfare}

Although this primer focuses on Atkinson's EDEI as a summary measure of societal wellbeing, many other measures of social welfare have been put forward and applied. (See Dollar and others, 2015, for a recent review and application.) Some of these measures share desirable features with Atkinson's EDEI. For example, Sen (1976) derives a simple social welfare function equal to mean income times one minus the Gini coefficient of a country's income distribution. Thus, Sen's social welfare is also expressed in monetary units (such as dollars); changes in social welfare can be decomposed into changes in mean income and changes in a well-known inequality measure; and it is rigorously derived from preference axioms. In empirical applications (as shown in the next section), country rankings based on Sen's social welfare index are similar, but not identical, to those obtained using Atkinson's EDEI.

\section{Relating Okun's Leaky Bucket Exercise to Optimal Income Taxation}

It may be helpful to show the relation of Okun's leaky bucket exercise to the analysis of optimal income taxation. In such analysis (see, for example, Piketty and Saez, 2013), social welfare is maximized subject to the constraint that tax revenues are at least as large as an exogenously-given minimum. Optimum income taxation models usually include sophisticated channels for the inefficiencies resulting from taxation - for example, lower worker effort. Okun's leaky bucket exercise includes only one distortion, the leak, which leaves the pre-taxand-transfer incomes of the rich and the poor unaffected. In the theory of optimum taxation, it is customary to report the "dollar value (in terms of public funds) of an extra dollar of consumption for each individual." In the leaky bucket setup, this translates to the extra welfare that would stem from an additional dollar of income provided to that individual, divided by the extra welfare that would stem from an additional dollar provided instead to the government, which would in turn allocate it optimally. Applying optimal-income-taxation-like thinking to the leaky bucket exercise, it can be shown that the dollar value (in terms of public 
funds) of an extra dollar of consumption will be equal to one, in the case of the poor; and to $1-b$, in the case of the rich (Appendix C).

\section{EMPirical APPLications}

The value for policy makers of the concepts outlined in the previous sections may be illustrated through their application to (a) assessing economic welfare in a panel of countries and (b) assessing policies such as a tax-and-transfer scheme.

\section{A. Average Incomes and Distribution for a Large Panel of Countries}

The approach outlined in the previous sections is illustrated by estimating the EDEI for a sample of 139 countries in 2015 using the dataset of Hellebrandt and Mauro (2016). ${ }^{8}$ The data are described in Box 1. The EDEI is measured in international U.S. dollars (that is, at purchasing power parity — considering international differences in prices). To facilitate crosscountry comparisons from the perspective of an external observer, a common coefficient of aversion to inequality is assumed for all countries in each exercise. Part of the reason inequality differs across countries may well be that societal preferences or political systems differ, but the purpose of the present exercise is to compare all countries using a common standard.

\section{Box 1: Income Distribution - Data from Household Surveys (continued)}

The data on income distribution are drawn from household surveys of thousands of people representative of each country's population. The analysis uses the best survey data available, primarily from the Luxembourg Income Study (LIS), which collects income survey data on many middle- and high-income countries; harmonizes them to enable cross-national comparisons; and makes them available for public use. Incomes are reported net of income taxes and include monetary transfers (but not in-kind transfers, subsidized goods and services, or public health or education provision). Information on countries not covered by the LIS is obtained from the World Bank database, which is largely based on consumption surveys. The mixing of consumption and income surveys is not ideal, but is appropriate and has become standard in the literature, given the data constraints. As Deaton (2005) notes: "consumption is typically much easier to measure in surveys than in income in poor countries, where many people are self-employed in agriculture, whereas the opposite in true in rich countries, where most people are wage earners and are more reluctant to cooperate with time-consuming consumption surveys."

Although household surveys are the most accurate source of data on income distribution, mean incomes or consumption from household surveys are often considerably different from (usually lower than) per capita GDP or consumption from the national accounts, as noted by many researchers (for example, Anand and Segal, 2008). The gap differs across countries (it is shown for most countries in Hellebrandt and Mauro, 2016, pp. 45-56).

The gap between GDP and mean household income (both per capita) stems in large part from the fact that GDP includes depreciation, retained earnings of corporations, and the part of government revenue (taxes) that is not distributed back to households as cash transfers. For example, in the case of the United States, disposable personal income in the national accounts was 72 percent of GDP in 2015.

${ }^{8}$ Available, internationally-comparable data for most countries do not provide detail regarding income distribution within households. The analysis focuses on household incomes divided by the number of people in the household. 


\section{Box 1: Income Distribution - Data from Household Surveys (concluded)}

The gap between aggregate household final consumption expenditure (HFCE) from the national accounts and survey household expenditure stems from more complex factors. Some sources of the differences are clearfor example, HFCE includes imputed rent from owner-occupied housing, which is rarely estimated in surveys. Other differences are not fully understood and likely stem from measurement errors. For example, in the national accounts, not only aggregate production but also the allocation of consumption between the government, private firms, and households can suffer from errors.

Measurement errors are also likely in the household surveys. For example, respondents may not always honestly report certain components of income. In particular, self-employed respondents who have understated their tax liability in tax returns may fear self-incrimination if they report their income accurately in surveys. Moreover, the surveys often under-sample high-income households, who tend to have lower response rates (perhaps because the opportunity cost of the time spent filling out a questionnaire rises with incomes). A novel approach to adjust the data for these two sources of error is used in Hellebrandt and Mauro (2016), though for simplicity the data in this primer are unadjusted. Inequality and its relative importance in EDEI would be somewhat stronger with adjusted data.

Figure 4 presents the relationship between EDEI and mean income (in logs) (Appendix Table 1 reports the full dataset). EDEI is computed using a high coefficient of inequality aversion (2.0) for expository purposes, both to emphasize the role of inequality and to improve legibility of the chart. Even with such a high coefficient, there is strong, positive association between the EDEI and mean income. ${ }^{9}$ At the same time, the ranking of countries based on the EDEI often differs significantly from that based on mean income alone. For instance, South Africa's mean income is more than double that of the Kyrgyz Republic, and substantially above that of Albania. However, those countries' lower inequality implies that their EDEI is significantly higher than South Africa's.

Such rank reversals and the extent of the differences in EDEI depend on observers' aversion to inequality (Table 3). Whereas South Africa's EDEI is above that of Albania or the Kyrgyz Republic for $\varepsilon=0.2$ or $\varepsilon=0.5$, the ranking is reversed for $\varepsilon=1.5$ or $\varepsilon=2.0$. Similarly, the United States' mean income is considerably above that of the United Kingdom or Sweden. However, for an inequality aversion coefficient of $\varepsilon=1.5$, Sweden's EDEI is above that of the United States, and for $\varepsilon=2.0$ also the United Kingdom's EDEI is above that of the United States.

\footnotetext{
${ }^{9}$ The same result holds using the Sen index (also reported in Appendix Table 1 for all countries in the sample). For the sample under consideration, the highest rank correlation between the Sen index and Atkinson's EDEI obtains when the latter is computed based on $\varepsilon=1.5$.
} 


\section{Figure 4. Mean Incomes and Equally-Distributed Equivalent Incomes (in logarithms)}

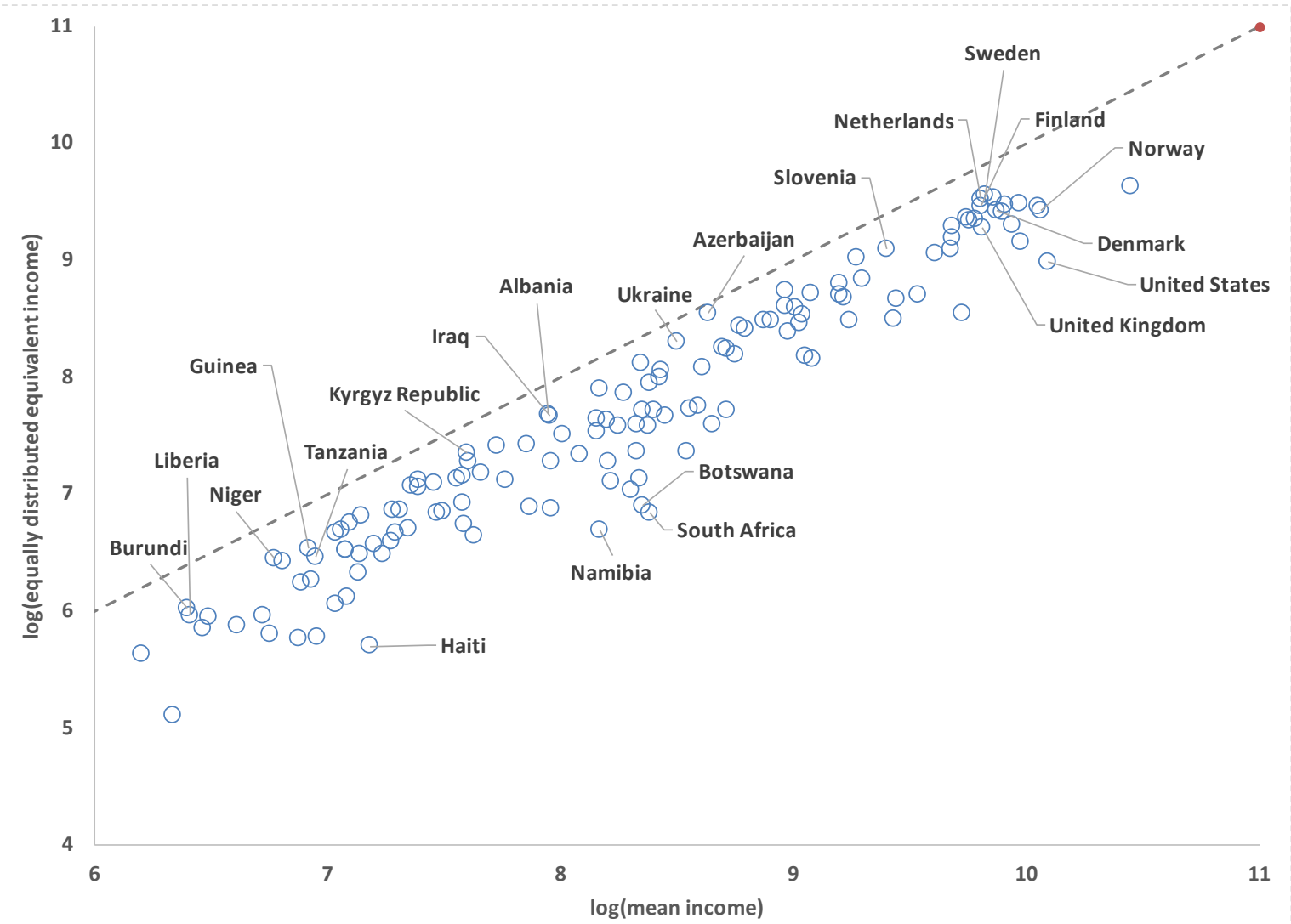

Note: Estimations are performed using $\varepsilon=2.0$. The data are reported in logarithms of 2011 U.S. international dollars (i.e., at purchasing power parity). Countries further below the dashed $45^{\circ}$ line are those with greater inequality as measured by the Atkinson index.

Source: Hellebrandt and Mauro (2016) and IMF staff calculations.

Table 3. Equally-Distributed-Equivalent Income for Different Inequality Aversion, 2015

\begin{tabular}{lrrrrr}
\hline \multicolumn{1}{c}{ Country } & Mean Income & \multicolumn{4}{c}{ EDEI } \\
\cline { 3 - 6 } & & $\varepsilon=0.2$ & $\varepsilon=0.5$ & $\varepsilon=1.5$ & \multicolumn{1}{c}{$\varepsilon=2.0$} \\
\hline United States & 24,128 & 22,781 & 20,880 & 14,404 & 7,985 \\
Sweden & 18,495 & 18,074 & 17,470 & 15,478 & 14,102 \\
United Kingdom & 18,176 & 17,419 & 16,373 & 13,141 & 10,623 \\
\hline South Africa & 4,366 & 3,679 & 2,848 & 1,323 & 931 \\
Albania & 2,835 & 2,757 & 2,646 & 2,305 & 2,151 \\
Kyrgyz Republic & 1,994 & 1,946 & 1,876 & 1,659 & 1,561 \\
\hline
\end{tabular}

Note: $\varepsilon$ denotes the coefficient of aversion to inequality. EDEI is the equally-distributed-equivalent income, i.e., the equallydistributed income that would make observers just as happy as the existing income distribution. EDEI and mean income are the same for an inequality aversion coefficient equal to zero.

Source: Hellebrandt and Mauro (2016) and IMF staff calculations.

Table 4 provides the summary of rank reversals for different measures of inequality aversion. It shows that rank reversals by two or more positions tend to increase with the degree of inequality aversion. 
Table 4. Rank Reversals

$\varepsilon=0.2 \quad \varepsilon=0.5 \quad \varepsilon=1.5 \quad \varepsilon=2.0$

\begin{tabular}{|c|c|c|c|c|}
\hline Number of countries with rank reversals ( 2 or more) & 18 & 35 & 69 & 71 \\
\hline (in percent of all countries in the sample) & 12.9 & 25.2 & 49.6 & 51.1 \\
\hline
\end{tabular}

Note: The sample consists of 139 countries. $\varepsilon$ is the inequality aversion coefficient. Rank reversals refer to a decline in the country's rank based on EDEI compared with the country's rank based on mean income. The table reports the number of countries experiencing rank reversals by two or more positions.

Figure 5 presents decomposition of changes in the EDEI between 2003-15 into mean income and income equality components (in logs) using the following equation: $\Delta \ln (\bar{I})=\Delta \ln (\mu)+$ $\Delta \ln (1-A)$. The analysis is performed using the same coefficient of inequality aversion (2.0) already used in Figure 4. It is apparent that, even using a high coefficient of aversion to inequality, most variation in the EDEI is accounted for by changes in mean incomes. Using lower inequality aversion coefficients (not reported, for the sake of brevity) leads to qualitatively similar results, with an even smaller role for changes in inequality. This result corroborates findings by Dollar and others (2015), who used a wide range of measures of social welfare.

To sum up, both cross-country differences in EDEI levels and changes in EDEI over the past decade are primarily driven by the level or changes in mean incomes, even when an external observer uses a high coefficient of inequality aversion to estimate EDEI. Levels or changes in inequality play a non-trivial, but smaller role. Even so, public policies have a sizable impact on inequality, and thus EDEI. In advanced economies, direct taxes and transfers reduce income inequality on average by about one third, with approximately three-quarters of this fiscal redistribution achieved on the transfer side of the budget (IMF, 2017).

\section{B. Assessment of Policies-Example: A Tax-and-Transfer Scheme}

As an illustration of how the EDEI can be used to summarize the effects of policies on both total income and its distribution, it is instructive to consider the impact of introducing a universal basic income (UBI, a subsidy paid to every citizen), with three alternative financing modalities, for the case of the United States, using a general equilibrium model applied to households (see Box 2, IMF 2017, and Lizarazo and others, 2017, for details). ${ }^{10}$ Specifically, the exercise considers the introduction of a UBI (cumulatively equivalent to 1 percent of GDP) financed by (a) cuts of spending assumed to be wholly wasteful (for the sake of

\footnotetext{
${ }^{10}$ This section was prepared with the help of Adrian Peralta-Alva. In this section, EDEI as a variable summarizing well-being is equally-distributed-equivalent consumption, to provide a fair comparison between VAT and PIT as potential sources of financing. Eden (2017) undertakes a similar exercise, in which she finds that, for most countries, a small increase in transfers financed by a uniform increase in labor income taxes would improve social welfare, using low coefficients of inequality aversion.
} 
Figure 5. Changes in EDEI and Its Components, cumulative over 2003-15
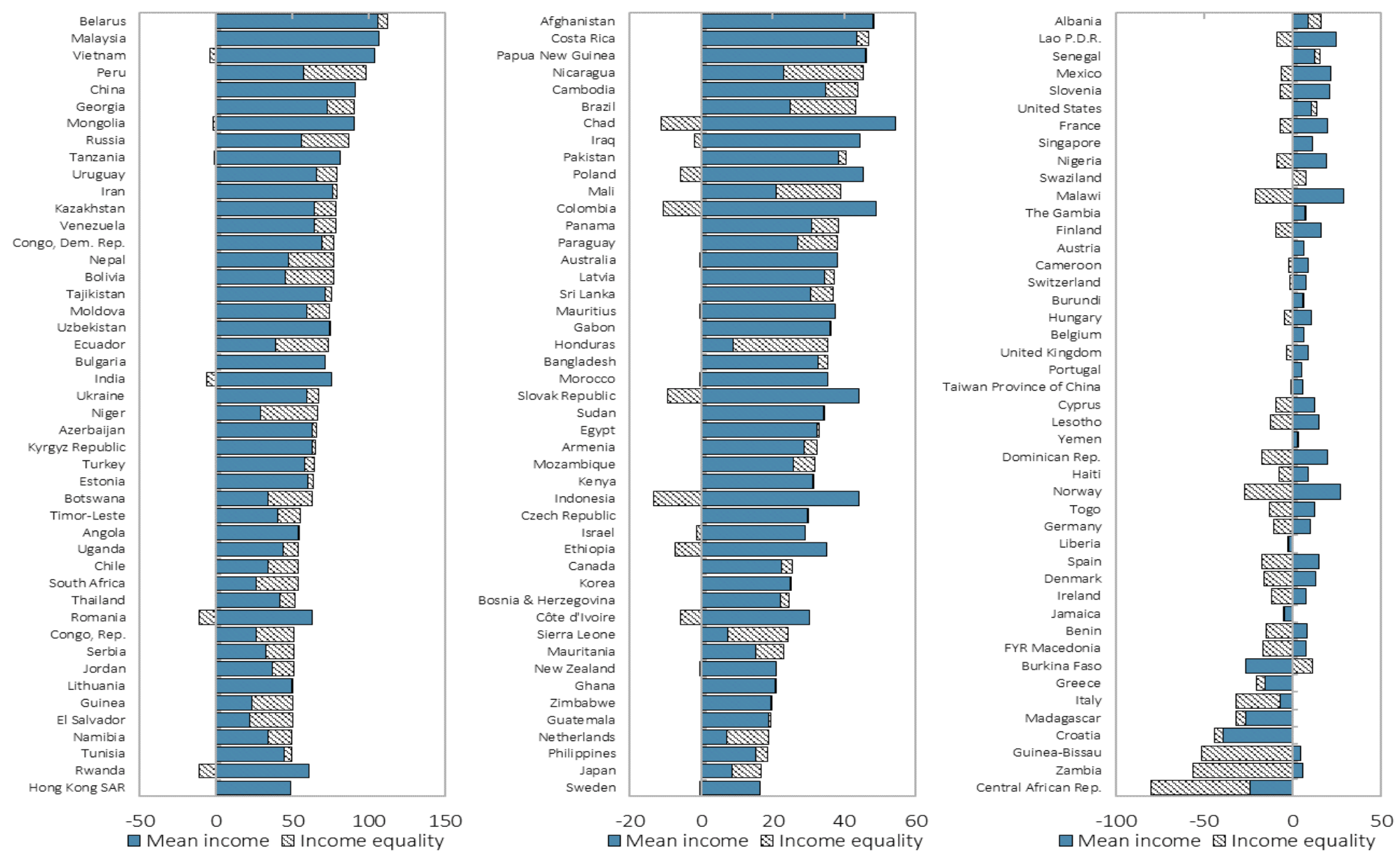

Note: Countries are ranked by the cumulative net improvement in equally-distributed-equivalent income (EDEI) during 2003-2015. Reported are contributions to changes in the EDEI from mean income and inequality. $\varepsilon=2.0$. Mean incomes and EDEI are in logarithms of 2011 U.S. international dollars (i.e., at purchasing power parity). Inequality is measured using the Atkinson index, as reported in the text.

Source: Hellebrandt and Mauro (2016) and IMF staff calculations. 
establishing a simple, theoretical benchmark), or (b) an increase in the personal income taxation (a progressive tax), or (c) the introduction of a value-added tax (a regressive tax).

\section{Box 2: Dynamic Stochastic General Equilibrium Model Used to Analyze the Potential Introduction of a Universal Basic Income}

Households are divided into predetermined types, differentiated by education level; they are subject to idiosyncratic productivity shocks, which generate income heterogeneity within household types. There are three industrial sectors - manufacturing, skilled services, and low-skilled services - each producing a different commodity with different technologies. Markets are assumed to be competitive. International trade occurs at prices determined in international markets. The government may hold an exogenously given level of external debt, with an exogenously given interest and amortization schedule; capital markets are otherwise closed.

Further assumptions include the following. First, as the horizon of analysis is the short to medium term (up to 5 years), each household's skill level is fixed. Second, low-skill individuals cannot work in the high-skill services sector. Third, the only vehicle for households to borrow or save is a (non-state contingent) bond; households also face exogenous borrowing constraints, which differ across skill levels.

A stationary equilibrium for this economy, taking international prices and the policy setting (taxes and transfer functions) as given, is such that households choices maximize their life-time expected utility and firms maximize profits. In addition, domestically determined prices (the interest rate, wages per skill level, and the prices of services) are such that markets clear and the government balances its budget.

Regardless of the source of financing, all curves in Figure 6 are upward sloping, because the benefits of introducing UBI (a policy that reduces inequality) are greater the higher is the coefficient of aversion to inequality.

When the UBI is financed by reductions in wasteful government spending, welfare increases regardless of the external observer's aversion to inequality. Such possibility is relevant in case a UBI substitutes for inequitable and inefficient public programs. The improvement is larger the greater the coefficient of aversion to inequality (Figure 6). In contrast, the net benefits would be lower, and could well be negative, in case the cuts applied to productive government spending or spending that carried a positive value for citizens.

The picture becomes even more complex when the UBI is financed through taxation. Comparing the PIT with the VAT as alternative revenue sources, the former is more desirable than the latter from the perspective of income distribution. (In the exercise, the PIT is assumed to become more progressive as reliance on it as a revenue source increases.) However, the PIT imposes greater efficiency costs, thus leading to lower total output than under VAT financing. Hence, other things equal, PIT financing is preferable when external observers are highly averse to inequality, whereas VAT financing does comparatively better for lower levels of inequality aversion. Even so, for low aversion to inequality, the efficiency costs prevail over the gains in equality, causing net losses in EDEI. For inequality aversion above 1.4, the introduction of a UBI financed by PIT provides net 
gains in EDEI, whereas a UBI financed by VAT would require very high inequality aversion, in excess of 2.4, to provide small net gains.

Figure 6. Gains in EDEI from the Introduction of UBI for Different Financing Sources

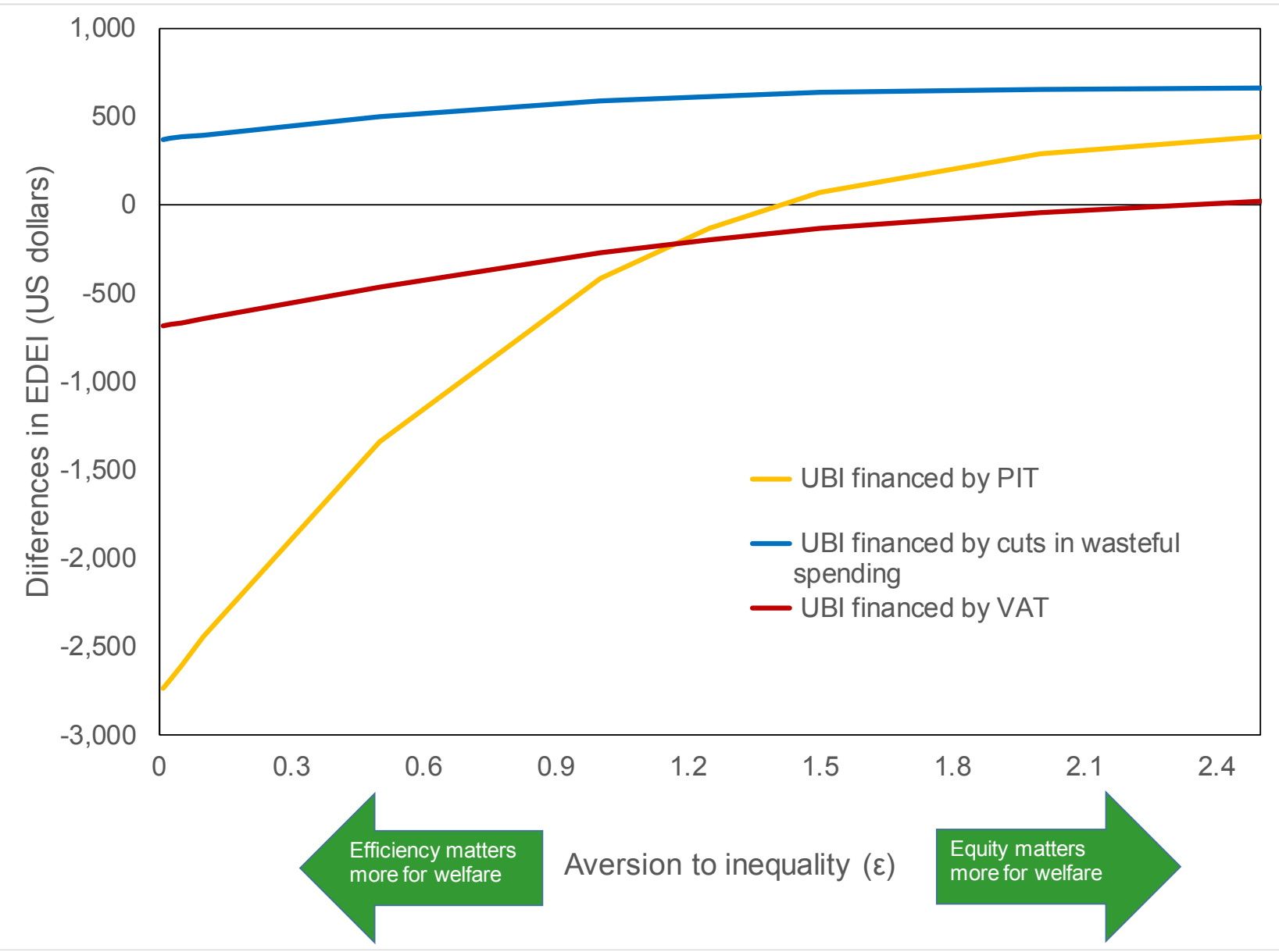

Note: The vertical axis reports the change in equally-distributed-equivalent income compared with the status quo, from introducing a universal basic income cumulatively equivalent to 1 percent of GDP. The coefficient of aversion to inequality is reported on the horizontal axis. The three alternative financing modalities are (i) cuts in spending assumed to be wasteful, (ii) increases in the personal income tax, or (iii) the introduction of a value-added tax. The results are based on a general equilibrium model applied to the United States (IMF 2017; Lizarazo and others 2017).

\section{Conclusion}

In view of rekindled interest in addressing income inequalities, policies in this area would benefit from being more systematically grounded in joint analyses of their implications for both efficiency and equity. To encourage more widespread use of such analyses, this primer has outlined a few important lessons from the "old masters" of economics, whose seminal contributions have gained renewed relevance for fiscal policymakers today. In particular, it has provided an in-depth refresher on methods developed by A. Okun and A. Atkinson to elicit people's views on inequality and to capture both output and its distribution in a single measure of social welfare; it has then applied such methods to recent data on income distribution for a large sample of countries. The analysis 
makes the case that using a monetary indicator that encompasses both total income and its distribution, such as the equally-distributed-equivalent income, is an especially helpful and intuitive tool for policymaking. The results show that, while economic growth plays a greater role than changes in income distribution in determining the evolution of the EDEI over periods spanning two decades, income distribution also plays a significant role. This primer has also summarized the results of a model-based application to a fiscal reform developed in IMF (2017), showing that policy choices depend to an important extent on the degree of aversion to inequality. Analysis using long-established, intuitive methods such as those presented here deserves greater attention and more frequent application in policymaking. 


\section{Appendix A. Deriving the Social Welfare Function (SWF)}

Per Blinder (1982), if the SWF is additive across individuals, and if the homotheticity assumptions holds, then the SWF must take the following form:

$$
\sum_{j=1}^{N}\left(A+B \frac{I_{j}^{1-\varepsilon}}{1-\varepsilon}\right)
$$

where $I_{j}$ is the income of individual $j, A$ and $B$ are constants, and $\varepsilon$ is the coefficient of inequality aversion.

This statement could be proved using two approaches.

Proof 1: additivity and homotheticity assumptions result in a constant elasticity SWF.

Additivity of the SWF implies:

$$
W=\sum_{j=1}^{N} w\left(I_{j}\right)
$$

where $w($.$) is an arbitrary function of an individual income contributing to the SWF.$

Following the leaky bucket experiment, the impartial observer is willing to transfer $\$ 1.00$ from individual $R$ (rich) to individual $P$ (poor) when the marginal leakage is $b$. From the first order condition, $b$ is defined by:

$$
\begin{aligned}
-w^{\prime}\left(I_{R}\right)+(1-b) \times w^{\prime}\left(I_{P}\right)=0 & \\
\frac{w^{\prime}\left(I_{P}\right)}{w^{\prime}\left(I_{R}\right)} & =\frac{1}{1-b}
\end{aligned}
$$

The homotheticity assumption implies:

$$
\frac{w^{\prime}\left(I_{P}\right)}{w^{\prime}\left(I_{R}\right)}=h\left(\frac{I_{P}}{I_{R}}\right)
$$

for some function $h($.$) . The question is which functional form h(\cdot)$ satisfies this equation.

Differentiating (B.5) by $I_{P}$ and $I_{R}$ gives:

$$
\begin{gathered}
\frac{w^{\prime \prime}\left(I_{P}\right)}{w^{\prime}\left(I_{R}\right)}=h^{\prime}\left(\frac{I_{P}}{I_{R}}\right) \times\left(\frac{1}{I_{R}}\right) \\
I_{R}: \quad \frac{-w^{\prime}\left(I_{P}\right) \times w^{\prime \prime}\left(I_{R}\right)}{\left[w^{\prime}\left(I_{R}\right)\right]^{2}}=h^{\prime}\left(\frac{I_{P}}{I_{R}}\right) \times\left(-\frac{I_{P}}{\left(I_{R}\right)^{2}}\right)
\end{gathered}
$$


Dividing B.6 over B.7 results in:

$$
\begin{gathered}
\frac{w^{\prime \prime}\left(I_{P}\right)}{w^{\prime}\left(I_{R}\right)} \times \frac{\left[w^{\prime}\left(I_{R}\right)\right]^{2}}{-w^{\prime}\left(I_{P}\right) \times w^{\prime \prime}\left(I_{R}\right)}=\frac{h^{\prime}\left(\frac{I_{P}}{I_{R}}\right) \times\left(\frac{1}{I_{R}}\right)}{h^{\prime}\left(\frac{I_{P}}{I_{R}}\right) \times\left(-\frac{I_{P}}{\left(I_{R}\right)^{2}}\right)} \\
\therefore-\left(\frac{w^{\prime \prime}\left(I_{P}\right) \times w^{\prime}\left(I_{R}\right)}{w^{\prime}\left(I_{P}\right) \times w^{\prime \prime}\left(I_{R}\right)}\right)=-\left(\frac{I_{R}}{I_{P}}\right) \\
\therefore \frac{I_{P} \times w^{\prime \prime}\left(I_{P}\right)}{w^{\prime}\left(I_{P}\right)}=\frac{I_{R} \times w^{\prime \prime}\left(I_{R}\right)}{w^{\prime}\left(I_{R}\right)}
\end{gathered}
$$

Note that the left-hand side of equation (B.8) is the elasticity of function $w^{\prime}\left(I_{P}\right)$, while the righthand side is the elasticity of function $w^{\prime}\left(I_{R}\right)$. Given that both elasticities are equal irrespective of level of income $\left(I_{P}\right.$ or $\left.I_{R}\right), w\left(I_{j}\right)$ should indeed be a constant elasticity function.

Proof 2: constant elasticity SWF should have functional form (B.1).

Another way to prove that (B.1) is the correct functional form for the SWF is to start from the constant elasticity assumption and show that the SWF should take the form (B.1).

Constant elasticity assumption:

$$
\begin{gathered}
\frac{w^{\prime \prime}(I) \times I}{w^{\prime}(I)}=-\varepsilon \\
\therefore \frac{w^{\prime \prime}(I)}{w^{\prime}(I)}=\frac{-\varepsilon}{I} \\
\therefore \frac{\mathrm{d}}{d I}\left(\log \left[w^{\prime}(I)\right]\right)=\frac{-\varepsilon}{I}
\end{gathered}
$$

where $\varepsilon$ is the constant elasticity.

Take the integral of both sides from $I_{0}$ to $I$, where $I_{0}$ is a constant:

$$
\begin{gathered}
\int_{I_{0}}^{I} \frac{\mathrm{d}}{d I}\left(\log \left[w^{\prime}(I)\right]\right) d I=\int_{I_{0}}^{I} \frac{-\varepsilon}{I} d I \\
\therefore \log \left(w^{\prime}(I)\right)-\log \left(w^{\prime}\left(I_{0}\right)\right)=-\varepsilon \times\left[\log (I)-\log \left(I_{0}\right)\right] \\
\therefore \log \left[\frac{w^{\prime}(I)}{w^{\prime}\left(I_{0}\right)}\right]=\log \left(\frac{I}{I_{0}}\right)^{-\varepsilon}
\end{gathered}
$$




$$
\begin{gathered}
\therefore \frac{w^{\prime}(I)}{w^{\prime}\left(I_{0}\right)}=\left(\frac{I}{I_{0}}\right)^{-\varepsilon} \\
\therefore \quad w^{\prime}(I)=\underbrace{w^{\prime}\left(I_{0}\right) \times\left(\frac{1}{I_{0}}\right)^{-\varepsilon}}_{\text {constant }} \times(I)^{-\varepsilon} \\
\therefore \quad w^{\prime}(I)=\text { const }_{1} \times(I)^{-\varepsilon}
\end{gathered}
$$

Where const is a constant.

Take the integral of both sides of (B.10):

$$
\begin{gathered}
\int w^{\prime}(I) d I=\int \text { const }_{1} \times(I)^{-\varepsilon} d I \\
\therefore w(I)+\text { const }_{2}=\text { const }_{1} \times \frac{I^{1-\varepsilon}}{1-\varepsilon}+\text { const }_{3}
\end{gathered}
$$

Regrouping the constants, $w(I)$ indeed takes the form (B.1). 


\section{Appendix B. Relating Atkinson's Inequality Index to Okun's Leaky Bucket}

Atkinson's inequality index bears an exact relationship to Okun's leaky bucket experiment.

Consider the simple case of two families with incomes $I_{R}$ and $I_{P}$. An observer is asked to assess the EDEI, $\bar{I}$, that would be just as desirable as the initial situation. $\bar{I}$ is lower than the mean initial income, $\mu$, defined as

$$
\mu \equiv \frac{1}{2}\left(I_{P}+I_{R}\right)
$$

The gap between $\bar{I}$ and $\mu$ will depend on the size of the transfer that needs to be made from the rich to the poor, the leakiness of the bucket, and the observer's aversion to inequality, $\varepsilon$.

The observer's inequality aversion will determine her choice of $\bar{I}$. In fact, from $\bar{I}$, and assuming the usual constant-inequality-aversion functional form used in the main text, it would be possible, if desired, to retrieve her coefficient of inequality aversion, by solving:

$$
w(\bar{I})=(1 / 2)\left[w\left(I_{P}\right)+w\left(I_{R}\right)\right]
$$

To simplify notation, define the percentage deviations of $I_{R}$ and $I_{P}$, respectively, from $\bar{I}$ :

$$
\gamma_{R} \equiv\left(I_{R}-\bar{I}\right) / \bar{I} \text { and } \gamma_{P} \equiv\left(\bar{I}-I_{P}\right) / \bar{I}
$$

It is useful to recall that:

$$
\mu=\bar{I}+\frac{1}{2}\left[\left(I_{R}-\bar{I}\right)-\left(\bar{I}-I_{P}\right)\right]
$$

And thus:

$$
\mu=\bar{I}\left[1+\frac{1}{2}\left(\gamma_{R}-\gamma_{P}\right)\right]
$$

The net transfer received by the poor will equal:

$$
\bar{I}-I_{P}=(1-b)\left(I_{R}-\bar{I}\right)
$$

where $b$ is the leakage coefficient and the gross transfer from the rich equals $I_{R}-\bar{I}$. This last expression is equivalent to:

$$
\gamma_{P}=(1-b) \gamma_{R}
$$

Recalling that Atkinson's inequality index, A, is the percentage loss in total income that would make the observer indifferent between the existing situation and one of perfect equality:

$$
A=1-\frac{\bar{I}}{\mu}
$$


Substituting the expression for mean income:

$$
A=1-\frac{\bar{I}}{\bar{I}\left[1+\frac{1}{2}\left(\gamma_{R}-\gamma_{P}\right)\right]}
$$

The gap $\gamma_{R}-\gamma_{P}$ is larger when initial inequality is large and when the observer is highly averse to inequality -in fact, such as observer would position $\bar{I}$ closer to $I_{P}$ and further from $I_{R}$.

From (A.7) and (A.5), it is possible to rewrite $A$ as either of two equivalent expressions:

$$
\begin{gathered}
A=1-\frac{1}{\left[1+\frac{1}{2} b \gamma_{R}\right]} \\
A=1-\frac{1}{\left[1+\frac{1}{2}\left(\frac{b}{1-b}\right) \gamma_{P}\right]}
\end{gathered}
$$

Each of these expressions links $A$ to both the observer's aversion to inequality (implicit in $\gamma_{R}$ or $\gamma_{P}$, the proportional distances between $\bar{I}$ and either $I_{P}$ or $I_{R}$, respectively) and to the leakage coefficient associated with the tax-and-transfer scheme that would equalize incomes at the level $\bar{I}$.

For the case of $n$ households, denoted $i=1, . . n$ and ranked by income, with $m$ the household earning $\bar{I}$, the analysis above holds by setting $I_{P}=\left(\frac{1}{m}\right) \sum_{i=1}^{m} I_{i}$ and $I_{R}=\left(\frac{1}{n-m}\right) \sum_{i=m}^{n} I_{i}$. 


\section{Appendix C. Relating Okun's Leaky Bucket Exercise to Optimal Income Taxation}

It may be helpful to show the consistency of Okun's leaky bucket exercise with the analysis of optimal income taxation. In such analysis (see, for example, Piketty and Saez, 2013), social welfare is maximized subject to the constraint that tax revenues are at least as large as an exogenouslygiven minimum. Optimum income taxation models usually include sophisticated channels for the inefficiencies resulting from taxation-for example, lower worker effort. Okun's leaky bucket exercise includes only one distortion, the leak, which - as a modeling shortcut-leaves the pre-taxand-transfer incomes of the rich and the poor unaffected. Applying optimal-income-taxation-like thinking to the leaky bucket exercise, the social welfare maximization problem may be presented as follows:

$$
\operatorname{Max} w\left(I_{P}+S_{P}\right)+w\left(I_{R}-T_{R}\right), \text { subject to: } R_{0}+(1-b) T_{R} \geq S_{P}
$$

where $I_{P}$ is initial income of the poor, $S_{P}$ is the subsidy received by (that is, negative tax on) the poor, $I_{R}$ is initial income of the rich, and $T_{R}$ is the tax levied on the rich. In the government's budget constraint, $S_{P}$ is the subsidy received from the poor. Revenues available to the government from taxing the rich are less than $T_{R}$, owing to the leak. $R_{0}$ represents exogenous revenues (say, from foreign aid or natural resources, whose collection does not lead to distortions) in excess of any exogenously-determined necessary spending.

The Lagrangean may thus be written as:

$$
L=w\left(I_{P}+S_{P}\right)+w\left(I_{R}-T_{R}\right)+\lambda\left[R_{0}+(1-b) T_{R}-S_{P}\right]
$$

Differentiation with respect to $S_{P}$ and $T_{R}$, respectively, yields the following first-order conditions:

$$
\begin{gathered}
w^{\prime}\left(I_{P}+S_{P}\right)=\lambda \\
w^{\prime}\left(I_{R}-T_{R}\right)=\lambda(1-b)
\end{gathered}
$$

These imply that the government will tax the rich to transfer to the poor up to the point where:

$$
w^{\prime}\left(I_{R}-T_{R}\right)=(1-b) w^{\prime}\left(I_{P}+S_{P}\right)
$$

Thus, whereas in the absence of the leak $(b=0)$ the government would equalize incomes of the two individuals, a positive leak implies that the government will let the incomes of the rich be above those of the poor. Indeed, at the optimum, the marginal welfare increase from extra income is higher for the poor than it is for the rich, implying that incomes are higher for the rich. The remaining income gap between the rich and the poor will be wider the larger the leak.

The Lagrange multiplier, $\lambda$, is the extra welfare that would stem from an additional dollar of $R_{0}$ given to the government for it to allocate optimally.

In the theory of optimum taxation, it is customary to report the "dollar value (in terms of public funds) of an extra dollar of consumption for each individual." In the present setup, this translates to the extra welfare that would stem from an additional dollar of income provided to that individual, divided by the extra welfare that would stem from an additional dollar provided instead to the 
government, which would in turn allocate it optimally. In other words, $w^{\prime}\left(I_{P}+S_{P}\right)$ for the poor or $w^{\prime}\left(I_{R}-T_{R}\right)$ for the rich-each divided by the Lagrange multiplier.

Thus, the dollar value (in terms of public funds) of an extra dollar of consumption will be equal to one, in the case of the poor; and to $1-b$, in the case of the rich. In fact, if the government received an extra dollar of $R_{0}$, it would certainly allocate it to the poor, thus raising social welfare by $w^{\prime}\left(I_{P}+S_{P}\right)$. Giving the extra dollar to the rich (instead of letting the government allocate it optimally - to the poor) would increase social welfare only by $w^{\prime}\left(I_{R}-T_{R}\right)=(1-b) w^{\prime}\left(I_{P}+S_{P}\right)$. 


\section{Appendix Table 1. Comparison of Country Ranks Based on Mean Income and Social Welfare (EDEI) (continued)}

\begin{tabular}{|c|c|c|c|c|c|c|c|c|c|c|c|c|c|}
\hline \multirow[t]{2}{*}{ Economy } & \multirow{2}{*}{$\begin{array}{l}\text { Mean } \\
\text { Income }\end{array}$} & \multicolumn{5}{|c|}{ EDEI Rank (Atkinson) } & \multicolumn{4}{|c|}{ EDEI (Atkinson) } & \multirow[t]{2}{*}{ Gini } & \multirow{2}{*}{$\begin{array}{c}\text { Sen } \\
\text { Index } \\
\text { Rank }\end{array}$} & \multirow{2}{*}{$\begin{array}{l}\text { Sen } \\
\text { Index }\end{array}$} \\
\hline & & $\varepsilon=0$ & $\varepsilon=0.2$ & $\varepsilon=0.5$ & $\varepsilon=1.5$ & $\varepsilon=\mathbf{2 . 0}$ & $\varepsilon=0.2$ & $\varepsilon=0.5$ & $\varepsilon=1.5$ & $\varepsilon=2.0$ & & & \\
\hline Hong Kong SAR & 34,428 & 1 & 1 & 1 & 2 & 1 & 31,731 & 28,085 & 18,730 & 15,302 & 0.48 & 1 & 18,026 \\
\hline United States & 24,128 & 2 & 3 & 4 & 13 & 24 & 22,781 & 20,880 & 14,404 & 7,985 & 0.40 & 5 & 14,405 \\
\hline Norway & 23,489 & 3 & 2 & 2 & 1 & 9 & 22,945 & 22,154 & 18,887 & 12,339 & 0.26 & 2 & 17,474 \\
\hline Switzerland & 23,200 & 4 & 4 & 3 & 3 & 7 & 22,411 & 21,296 & 17,529 & 12,900 & 0.32 & 3 & 15,869 \\
\hline Singapore & 21,500 & 5 & 7 & 11 & 20 & 19 & 19,800 & 17,503 & 11,612 & 9,460 & 0.48 & 18 & 11,211 \\
\hline Canada & 21,417 & 6 & 5 & 5 & 6 & 5 & 20,586 & 19,414 & 15,645 & 13,192 & 0.33 & 6 & 14,260 \\
\hline Australia & 20,748 & 7 & 6 & 6 & 12 & 15 & 19,921 & 18,749 & 14,804 & 10,941 & 0.34 & 10 & 13,637 \\
\hline Germany & 20,100 & 8 & 8 & 7 & 4 & 6 & 19,473 & 18,588 & 15,804 & 13,040 & 0.30 & 7 & 14,021 \\
\hline Austria & 19,893 & 9 & 9 & 8 & 7 & 11 & 19,280 & 18,413 & 15,514 & 12,183 & 0.30 & 8 & 13,938 \\
\hline Denmark & 19,328 & 10 & 10 & 9 & 5 & 10 & 18,888 & 18,257 & 15,751 & 12,322 & 0.25 & 4 & 14,450 \\
\hline New Zealand & 19,164 & 11 & 11 & 10 & 10 & 3 & 18,536 & 17,631 & 14,923 & 13,729 & 0.32 & 12 & 13,089 \\
\hline Sweden & 18,495 & 12 & 12 & 12 & 8 & 2 & 18,074 & 17,470 & 15,478 & 14,102 & 0.26 & 9 & 13,742 \\
\hline United Kingdom & 18,176 & 13 & 15 & 15 & 16 & 17 & 17,419 & 16,373 & 13,141 & 10,623 & 0.35 & 16 & 11,894 \\
\hline Finland & 18,159 & 14 & 13 & 13 & 9 & 8 & 17,710 & 17,072 & 15,000 & 12,817 & 0.27 & 11 & 13,270 \\
\hline Netherlands & 18,128 & 15 & 14 & 14 & 11 & 4 & 17,641 & 16,952 & 14,846 & 13,689 & 0.28 & 13 & 13,054 \\
\hline France & 17,716 & 16 & 16 & 16 & 15 & 13 & 17,087 & 16,203 & 13,403 & 11,551 & 0.32 & 15 & 12,069 \\
\hline Belgium & 17,297 & 17 & 17 & 17 & 14 & 14 & 16,778 & 16,068 & 13,757 & 11,346 & 0.29 & 14 & 12,365 \\
\hline Taiwan, POC & 17,013 & 18 & 18 & 18 & 17 & 12 & 16,396 & 15,540 & 13,028 & 11,674 & 0.32 & 17 & 11,497 \\
\hline Puerto Rico & 16,735 & 19 & 22 & 23 & 33 & 36 & 14,861 & 12,439 & 6,885 & 5,123 & 0.56 & 28 & 7,385 \\
\hline Portugal & 16,065 & 20 & 19 & 20 & 18 & 16 & 15,447 & 14,565 & 11,973 & 10,856 & 0.34 & 21 & 10,570 \\
\hline Ireland & 15,984 & 21 & 20 & 19 & 19 & 18 & 15,435 & 14,642 & 11,959 & 9,801 & 0.32 & 19 & 10,895 \\
\hline Korea & 15,882 & 22 & 21 & 21 & 21 & 20 & 15,306 & 14,472 & 11,506 & 8,857 & 0.33 & 20 & 10,709 \\
\hline Japan & 14,882 & 23 & 23 & 22 & 22 & 22 & 14,350 & 13,583 & 10,878 & 8,570 & 0.32 & 22 & 10,103 \\
\hline Spain & 13,848 & 24 & 24 & 24 & 24 & 30 & 13,244 & 12,345 & 8,969 & 6,021 & 0.36 & 23 & 8,867 \\
\hline Israel & 12,651 & 25 & 25 & 27 & 28 & 32 & 11,919 & 10,872 & 7,615 & 5,795 & 0.41 & 27 & 7,431 \\
\hline Italy & 12,440 & 26 & 26 & 26 & 26 & 38 & 11,908 & 11,138 & 8,154 & 4,911 & 0.35 & 25 & 8,083 \\
\hline Slovenia & 12,086 & 27 & 27 & 25 & 23 & 21 & 11,769 & 11,314 & 9,787 & 8,851 & 0.27 & 24 & 8,788 \\
\hline Lebanon & 10,923 & 28 & 28 & 29 & 27 & 25 & 10,428 & 9,727 & 7,712 & 6,867 & 0.37 & 29 & 6,882 \\
\hline Czech Rep. & 10,636 & 29 & 29 & 28 & 25 & 23 & 10,373 & 9,998 & 8,839 & 8,257 & 0.27 & 26 & 7,810 \\
\hline Malaysia & 10,323 & 30 & 31 & 33 & 39 & 40 & 9,566 & 8,534 & 5,834 & 4,823 & 0.46 & 36 & 5,547 \\
\hline Greece & 10,085 & 31 & 30 & 30 & 30 & 31 & 9,687 & 9,121 & 7,230 & 5,862 & 0.34 & 30 & 6,686 \\
\hline Estonia & 9,863 & 32 & 32 & 31 & 31 & 29 & 9,502 & 8,977 & 7,180 & 6,052 & 0.33 & 31 & 6,647 \\
\hline Cyprus & 9,860 & 33 & 33 & 32 & 29 & 26 & 9,479 & 8,934 & 7,334 & 6,645 & 0.34 & 32 & 6,477 \\
\hline Chile & 8,794 & 34 & 36 & 40 & 47 & 51 & 8,013 & 6,970 & 4,380 & 3,472 & 0.50 & 46 & 4,357 \\
\hline Slovak Rep. & 8,737 & 35 & 34 & 34 & 32 & 28 & 8,508 & 8,174 & 6,951 & 6,079 & 0.27 & 33 & 6,373 \\
\hline Costa Rica & 8,517 & 36 & 39 & 42 & 46 & 50 & 7,803 & 6,842 & 4,416 & 3,548 & 0.49 & 47 & 4,328 \\
\hline Russia & 8,422 & 37 & 35 & 35 & 35 & 37 & 8,118 & 7,678 & 6,162 & 5,056 & 0.32 & 35 & 5,687 \\
\hline Poland & 8,301 & 38 & 37 & 36 & 38 & 42 & 7,966 & 7,492 & 5,941 & 4,747 & 0.34 & 37 & 5,458 \\
\hline Lithuania & 8,180 & 39 & 38 & 38 & 36 & 34 & 7,847 & 7,373 & 5,989 & 5,398 & 0.35 & 38 & 5,305 \\
\hline Uruguay & 7,929 & 40 & 42 & 41 & 43 & 45 & 7,485 & 6,874 & 5,185 & 4,408 & 0.41 & 42 & 4,713 \\
\hline Bosnia and Herz. & 7,844 & 41 & 41 & 39 & 37 & 33 & 7,564 & 7,162 & 5,969 & 5,450 & 0.33 & 39 & 5,252 \\
\hline Belarus & 7,808 & 42 & 40 & 37 & 34 & 27 & 7,638 & 7,390 & 6,618 & 6,264 & 0.26 & 34 & 5,777 \\
\hline Latvia & 7,370 & 43 & 43 & 43 & 41 & 41 & 7,064 & 6,629 & 5,362 & 4,823 & 0.35 & 41 & 4,755 \\
\hline Hungary & 7,145 & 44 & 44 & 44 & 40 & 39 & 6,908 & 6,562 & 5,424 & 4,829 & 0.31 & 40 & 4,919 \\
\hline Jordan & 6,586 & 45 & 45 & 45 & 45 & 44 & 6,340 & 5,989 & 4,954 & 4,506 & 0.34 & 45 & 4,367 \\
\hline Croatia & 6,440 & 46 & 46 & 46 & 44 & 43 & 6,225 & 5,915 & 4,991 & 4,585 & 0.32 & 44 & 4,380 \\
\hline Turkey & 6,324 & 47 & 47 & 47 & 51 & 49 & 5,983 & 5,505 & 4,170 & 3,630 & 0.40 & 50 & 3,784 \\
\hline Iran & 6,089 & 48 & 48 & 49 & 49 & 48 & 5,808 & 5,409 & 4,269 & 3,792 & 0.37 & 49 & 3,815 \\
\hline Panama & 6,068 & 49 & 51 & 51 & 58 & 61 & 5,537 & 4,818 & 2,947 & 2,253 & 0.50 & 55 & 3,029 \\
\hline Bulgaria & 5,965 & 50 & 49 & 50 & 48 & 47 & 5,709 & 5,347 & 4,296 & 3,850 & 0.36 & 48 & 3,817 \\
\hline Paraguay & 5,723 & 51 & 53 & 54 & 62 & 70 & 5,166 & 4,474 & 2,793 & 1,987 & 0.51 & 57 & 2,817 \\
\hline Azerbaijan & 5,622 & 52 & 50 & 48 & 42 & 35 & 5,573 & 5,499 & 5,262 & 5,147 & 0.17 & 43 & 4,687 \\
\hline Thailand & 5,471 & 53 & 52 & 52 & 52 & 53 & 5,190 & 4,795 & 3,682 & 3,227 & 0.39 & 52 & 3,323 \\
\hline
\end{tabular}




\begin{tabular}{|c|c|c|c|c|c|c|c|c|c|c|c|c|c|}
\hline \multirow[t]{2}{*}{ Economy } & \multirow{2}{*}{$\begin{array}{l}\text { Mean } \\
\text { Income }\end{array}$} & \multicolumn{5}{|c|}{ EDEI Rank (Atkinson) } & \multicolumn{4}{|c|}{ EDEI (Atkinson) } & \multirow[t]{2}{*}{ Gini } & \multirow{2}{*}{$\begin{array}{c}\text { Sen } \\
\text { Index } \\
\text { Rank }\end{array}$} & \multirow{2}{*}{$\begin{array}{l}\text { Sen } \\
\text { Index }\end{array}$} \\
\hline & & $\varepsilon=0$ & $\varepsilon=0.2$ & $\varepsilon=0.5$ & $\varepsilon=1.5$ & $\varepsilon=2.0$ & $\varepsilon=0.2$ & $\varepsilon=0.5$ & $\varepsilon=1.5$ & $\varepsilon=2.0$ & & & \\
\hline Brazil & 5,387 & 54 & 54 & 55 & 60 & 59 & 4,953 & 4,372 & 2,884 & 2,325 & 0.48 & 59 & 2,809 \\
\hline Bolivia & 5,197 & 55 & 56 & 56 & 63 & 60 & 4,783 & 4,223 & 2,788 & 2,265 & 0.48 & 61 & 2,699 \\
\hline Dominican Rep. & 5,124 & 56 & 57 & 60 & 71 & 78 & 4,602 & 3,934 & 2,308 & 1,576 & 0.53 & 66 & 2,411 \\
\hline Ukraine & 4,907 & 57 & 55 & 53 & 50 & 46 & 4,812 & 4,673 & 4,238 & 4,035 & 0.25 & 51 & 3,702 \\
\hline Venezuela & 4,671 & 58 & 60 & 62 & 65 & 66 & 4,318 & 3,838 & 2,590 & 2,127 & 0.47 & 65 & 2,479 \\
\hline Mongolia & 4,599 & 59 & 58 & 57 & 54 & 54 & 4,427 & 4,181 & 3,456 & 3,142 & 0.34 & 54 & 3,047 \\
\hline Mauritius & 4,571 & 60 & 59 & 58 & 55 & 55 & 4,377 & 4,102 & 3,303 & 2,964 & 0.36 & 56 & 2,933 \\
\hline FYR Macedonia & 4,445 & 61 & 62 & 64 & 64 & 62 & 4,152 & 3,749 & 2,667 & 2,249 & 0.44 & 64 & 2,487 \\
\hline Tunisia & 4,382 & 62 & 61 & 61 & 56 & 56 & 4,197 & 3,933 & 3,168 & 2,843 & 0.36 & 58 & 2,813 \\
\hline South Africa & 4,366 & 63 & 70 & 78 & 93 & 102 & 3,679 & 2,848 & 1,323 & 931 & 0.65 & 86 & 1,529 \\
\hline Ecuador & 4,348 & 64 & 65 & 65 & 67 & 72 & 4,014 & 3,560 & 2,386 & 1,954 & 0.47 & 67 & 2,292 \\
\hline Botswana & 4,234 & 65 & 71 & 77 & 89 & 96 & 3,664 & 2,950 & 1,432 & 996 & 0.60 & 83 & 1,674 \\
\hline Serbia & 4,231 & 66 & 64 & 63 & 57 & 63 & 4,062 & 3,816 & 2,947 & 2,239 & 0.34 & 60 & 2,779 \\
\hline Kazakhstan & 4,224 & 67 & 63 & 59 & 53 & 52 & 4,129 & 3,992 & 3,564 & 3,368 & 0.26 & 53 & 3,111 \\
\hline Peru & 4,188 & 68 & 66 & 68 & 77 & 87 & 3,868 & 3,415 & 1,984 & 1,247 & 0.47 & 69 & 2,232 \\
\hline Jamaica & 4,149 & 69 & 67 & 67 & 66 & 69 & 3,856 & 3,455 & 2,397 & 1,997 & 0.45 & 68 & 2,263 \\
\hline Mexico & 4,133 & 70 & 68 & 70 & 75 & 77 & 3,751 & 3,266 & 2,093 & 1,581 & 0.50 & 73 & 2,059 \\
\hline Colombia & 4,035 & 71 & 72 & 74 & 83 & 94 & 3,582 & 3,021 & 1,706 & 1,132 & 0.55 & 79 & 1,822 \\
\hline Romania & 3,907 & 72 & 69 & 66 & 61 & 58 & 3,751 & 3,527 & 2,875 & 2,596 & 0.35 & 62 & 2,544 \\
\hline El Salvador & 3,809 & 73 & 73 & 71 & 70 & 71 & 3,565 & 3,228 & 2,317 & 1,964 & 0.44 & 71 & 2,152 \\
\hline Guatemala & 3,699 & 74 & 77 & 79 & 85 & 90 & 3,313 & 2,817 & 1,650 & 1,224 & 0.54 & 81 & 1,709 \\
\hline China & 3,653 & 75 & 76 & 76 & 78 & 81 & 3,363 & 2,963 & 1,888 & 1,455 & 0.48 & 77 & 1,885 \\
\hline Morocco & 3,641 & 76 & 75 & 72 & 69 & 68 & 3,439 & 3,156 & 2,371 & 2,055 & 0.41 & 70 & 2,159 \\
\hline Moldova & 3,535 & 77 & 74 & 69 & 59 & 57 & 3,442 & 3,307 & 2,893 & 2,706 & 0.29 & 63 & 2,527 \\
\hline Namibia & 3,526 & 78 & 80 & 85 & 100 & 109 & 3,042 & 2,438 & 1,165 & 803 & 0.61 & 88 & 1,376 \\
\hline Vietnam & 3,483 & 79 & 78 & 73 & 68 & 67 & 3,309 & 3,065 & 2,373 & 2,088 & 0.39 & 72 & 2,135 \\
\hline Gabon & 3,475 & 80 & 79 & 75 & 74 & 73 & 3,266 & 2,977 & 2,185 & 1,872 & 0.42 & 75 & 2,009 \\
\hline Nicaragua & 3,246 & 81 & 81 & 80 & 79 & 80 & 3,014 & 2,697 & 1,862 & 1,547 & 0.46 & 80 & 1,762 \\
\hline Sri Lanka & 3,017 & 82 & 82 & 81 & 76 & 74 & 2,868 & 2,657 & 2,061 & 1,815 & 0.39 & 78 & 1,853 \\
\hline Honduras & 2,859 & 83 & 86 & 87 & 96 & 98 & 2,567 & 2,185 & 1,276 & 974 & 0.54 & 92 & 1,325 \\
\hline Georgia & 2,857 & 84 & 85 & 84 & 81 & 82 & 2,696 & 2,471 & 1,822 & 1,454 & 0.41 & 82 & 1,691 \\
\hline Iraq & 2,851 & 85 & 83 & 82 & 73 & 65 & 2,771 & 2,654 & 2,298 & 2,139 & 0.30 & 76 & 2,009 \\
\hline Albania & 2,835 & 86 & 84 & 83 & 72 & 64 & 2,757 & 2,646 & 2,305 & 2,151 & 0.29 & 74 & 2,014 \\
\hline Egypt & 2,618 & 87 & 88 & 89 & 95 & 97 & 2,346 & 2,019 & 1,278 & 978 & 0.52 & 94 & 1,260 \\
\hline Yemen & 2,575 & 88 & 87 & 86 & 80 & 75 & 2,466 & 2,310 & 1,858 & 1,667 & 0.36 & 84 & 1,651 \\
\hline Philippines & 2,354 & 89 & 89 & 90 & 88 & 88 & 2,207 & 2,003 & 1,449 & 1,233 & 0.43 & 90 & 1,341 \\
\hline Tajikistan & 2,276 & 90 & 90 & 88 & 82 & 76 & 2,206 & 2,105 & 1,799 & 1,664 & 0.31 & 85 & 1,576 \\
\hline Mauritania & 2,121 & 91 & 91 & 91 & 87 & 84 & 2,022 & 1,883 & 1,483 & 1,316 & 0.37 & 91 & 1,326 \\
\hline India & 2,056 & 92 & 95 & 97 & 106 & 112 & 1,872 & 1,632 & 1,034 & 768 & 0.50 & 102 & 1,026 \\
\hline Armenia & 2,009 & 93 & 93 & 93 & 86 & 83 & 1,943 & 1,849 & 1,568 & 1,444 & 0.32 & 89 & 1,375 \\
\hline Kyrgyz Rep. & 1,994 & 94 & 92 & 92 & 84 & 79 & 1,946 & 1,876 & 1,659 & 1,561 & 0.27 & 87 & 1,448 \\
\hline Kenya & 1,969 & 95 & 98 & 98 & 105 & 106 & 1,809 & 1,593 & 1,042 & 843 & 0.49 & 103 & 1,014 \\
\hline Sudan & 1,960 & 96 & 94 & 94 & 90 & 85 & 1,879 & 1,764 & 1,429 & 1,286 & 0.35 & 93 & 1,266 \\
\hline Côte d'Ivoire & 1,957 & 97 & 96 & 96 & 99 & 95 & 1,834 & 1,663 & 1,201 & 1,020 & 0.43 & 98 & 1,112 \\
\hline Indonesia & 1,912 & 98 & 97 & 95 & 91 & 86 & 1,832 & 1,719 & 1,389 & 1,248 & 0.36 & 95 & 1,232 \\
\hline Cameroon & 1,801 & 99 & 99 & 100 & 101 & 101 & 1,689 & 1,535 & 1,115 & 950 & 0.43 & 101 & 1,030 \\
\hline Ghana & 1,760 & 100 & 101 & 102 & 102 & 103 & 1,651 & 1,500 & 1,091 & 930 & 0.43 & 104 & 1,007 \\
\hline Nepal & 1,734 & 101 & 100 & 99 & 92 & 91 & 1,673 & 1,586 & 1,327 & 1,213 & 0.33 & 96 & 1,166 \\
\hline Afghanistan & 1,623 & 102 & 102 & 101 & 94 & 89 & 1,579 & 1,514 & 1,319 & 1,231 & 0.29 & 97 & 1,152 \\
\hline Cambodia & 1,620 & 103 & 103 & 103 & 98 & 93 & 1,567 & 1,490 & 1,259 & 1,158 & 0.32 & 100 & 1,105 \\
\hline Pakistan & 1,571 & 104 & 104 & 104 & 97 & 92 & 1,526 & 1,461 & 1,265 & 1,177 & 0.30 & 99 & 1,106 \\
\hline Angola & 1,548 & 105 & 105 & 106 & 108 & 107 & 1,453 & 1,321 & 961 & 819 & 0.43 & 107 & 887 \\
\hline Lao P.D.R. & 1,493 & 106 & 106 & 105 & 103 & 99 & 1,428 & 1,336 & 1,070 & 958 & 0.36 & 105 & 952 \\
\hline Zimbabwe & 1,469 & 107 & 108 & 108 & 110 & 111 & 1,380 & 1,257 & 921 & 788 & 0.42 & 109 & 848 \\
\hline Uzbekistan & 1,447 & 108 & 107 & 107 & 104 & 100 & 1,388 & 1,303 & 1,057 & 952 & 0.35 & 106 & 937 \\
\hline Papua New Guinea & 1,443 & 109 & 109 & 109 & 112 & 113 & 1,348 & 1,219 & 869 & 734 & 0.44 & 111 & 810 \\
\hline
\end{tabular}




\begin{tabular}{|c|c|c|c|c|c|c|c|c|c|c|c|c|c|}
\hline \multirow[t]{2}{*}{ Economy } & \multirow{2}{*}{$\begin{array}{c}\text { Mean } \\
\text { Income }\end{array}$} & \multicolumn{5}{|c|}{ EDEI Rank (Atkinson) } & \multicolumn{4}{|c|}{ EDEI (Atkinson) } & \multirow[t]{2}{*}{ Gini } & \multirow{2}{*}{$\begin{array}{c}\text { Sen } \\
\text { Index } \\
\text { Rank }\end{array}$} & \multirow[t]{2}{*}{$\begin{array}{l}\text { Sen } \\
\text { Index }\end{array}$} \\
\hline & & $\varepsilon=\mathbf{0}$ & $\varepsilon=0.2$ & $\varepsilon=0.5$ & $\varepsilon=1.5$ & $\varepsilon=2.0$ & $\varepsilon=0.2$ & $\varepsilon=0.5$ & $\varepsilon=1.5$ & $\varepsilon=2.0$ & & & \\
\hline Togo & 1,386 & 110 & 110 & 111 & 115 & 118 & 1,286 & 1,149 & 789 & 653 & 0.46 & 115 & 748 \\
\hline Uganda & 1,338 & 111 & 111 & 112 & 114 & 114 & 1,257 & 1,144 & 837 & 716 & 0.42 & 113 & 771 \\
\hline Haiti & 1,315 & 112 & 116 & 123 & 131 & 137 & 1,136 & 911 & 436 & 299 & 0.61 & 128 & 515 \\
\hline Timor-Leste & 1,268 & 113 & 112 & 110 & 107 & 104 & 1,227 & 1,168 & 990 & 911 & 0.32 & 108 & 868 \\
\hline Chad & 1,259 & 114 & 113 & 114 & 118 & 119 & 1,179 & 1,068 & 769 & 653 & 0.43 & 116 & 714 \\
\hline Gambia, The & 1,250 & 115 & 115 & 119 & 121 & 123 & 1,154 & 1,023 & 685 & 560 & 0.47 & 120 & 658 \\
\hline Bangladesh & 1,204 & 116 & 114 & 113 & 109 & 105 & 1,164 & 1,105 & 931 & 854 & 0.32 & 110 & 817 \\
\hline Rwanda & 1,194 & 117 & 121 & 120 & 126 & 126 & 1,084 & 938 & 577 & 452 & 0.51 & 124 & 581 \\
\hline Congo, Rep. of & 1,184 & 118 & 117 & 117 & 116 & 116 & 1,120 & 1,031 & 781 & 680 & 0.40 & 117 & 709 \\
\hline Senegal & 1,184 & 119 & 119 & 118 & 117 & 117 & 1,120 & 1,030 & 779 & 677 & 0.40 & 118 & 707 \\
\hline Ethiopia & 1,162 & 120 & 118 & 115 & 111 & 108 & 1,120 & 1,060 & 882 & 805 & 0.33 & 112 & 777 \\
\hline Mali & 1,135 & 121 & 120 & 116 & 113 & 110 & 1,094 & 1,036 & 864 & 788 & 0.33 & 114 & 760 \\
\hline Swaziland & 1,134 & 122 & 122 & 124 & 127 & 127 & 1,029 & 889 & 546 & 427 & 0.51 & 127 & 551 \\
\hline Zambia & 1,049 & 123 & 126 & 129 & 132 & 135 & 933 & 782 & 434 & 322 & 0.56 & 129 & 466 \\
\hline Tanzania & 1,045 & 124 & 123 & 121 & 120 & 120 & 995 & 925 & 726 & 643 & 0.38 & 121 & 650 \\
\hline Benin & 1,023 & 125 & 125 & 125 & 124 & 124 & 957 & 867 & 623 & 528 & 0.43 & 125 & 578 \\
\hline Guinea & 1,012 & 126 & 124 & 122 & 119 & 115 & 974 & 920 & 761 & 692 & 0.34 & 119 & 671 \\
\hline Nigeria & 979 & 127 & 127 & 126 & 125 & 125 & 918 & 834 & 604 & 514 & 0.43 & 126 & 558 \\
\hline Lesotho & 969 & 128 & 129 & 130 & 135 & 136 & 868 & 736 & 424 & 320 & 0.54 & 131 & 444 \\
\hline Sierra Leone & 907 & 129 & 128 & 127 & 123 & 122 & 873 & 823 & 678 & 616 & 0.34 & 123 & 599 \\
\hline Niger & 874 & 130 & 130 & 128 & 122 & 121 & 846 & 805 & 683 & 630 & 0.31 & 122 & 599 \\
\hline Guinea-Bissau & 856 & 131 & 131 & 132 & 136 & 134 & 779 & 677 & 423 & 333 & 0.51 & 132 & 422 \\
\hline Malawi & 830 & 132 & 132 & 131 & 128 & 129 & 770 & 687 & 471 & 389 & 0.46 & 130 & 447 \\
\hline Mozambique & 743 & 133 & 133 & 133 & 134 & 132 & 691 & 619 & 428 & 355 & 0.46 & 133 & 405 \\
\hline Burkina Faso & 659 & 134 & 134 & 134 & 130 & 131 & 624 & 575 & 438 & 382 & 0.40 & 135 & 397 \\
\hline DR of the Congo & 642 & 135 & 135 & 135 & 137 & 133 & 604 & 551 & 404 & 346 & 0.42 & 137 & 372 \\
\hline Liberia & 608 & 136 & 136 & 137 & 133 & 130 & 581 & 543 & 433 & 387 & 0.36 & 136 & 386 \\
\hline Burundi & 600 & 137 & 137 & 136 & 129 & 128 & 578 & 547 & 454 & 413 & 0.33 & 134 & 400 \\
\hline Cent. Afr. Rep. & 565 & 138 & 138 & 139 & 139 & 139 & 501 & 418 & 227 & 165 & 0.56 & 139 & 247 \\
\hline Madagascar & 494 & 139 & 139 & 138 & 138 & 138 & 466 & 428 & 322 & 279 & 0.41 & 138 & 293 \\
\hline
\end{tabular}

Note: $\varepsilon$ is the inequality aversion parameter. Mean incomes are taken from the household surveys and are measured in 2011 U.S. international dollars (i.e., at purchasing power parity). EDEI is the equally-distributed-equivalent income, i.e., the equally-distributed income that would make observers just as happy as the existing income distribution. EDEI is identical to mean income for $\varepsilon=0$. Sen's index is defined as mean income times one minus the Gini coefficient; its units are the same as for mean income and the EDEI.

Source: Hellebrandt and Mauro (2016) and IMF staff calculations. 


\section{References}

Amiel, Y. and Cowell, F. A., 1999, Thinking about Inequality, Cambridge University Press.

Anand, Sudhir, and Paul Segal, 2008, "What Do We Know about Global Income Inequality?" Journal of Economic Literature, Vol. 46, No. 1, pp. 57-94.

Atkinson, Anthony B., 1970, “On the Measurement of Inequality,” Journal of Economic Theory, Vol. 2, pp. 244-263.

Bargain, Olivier, Mathias Dolls, Dirk Neumann, Andreas Peichl, and Sebastian Siegloch, 2014, "Comparing Inequality Aversion across Countries when Labor Supply Responses Differ," International Tax and Public Finance, Vol. 21, pp. 845-873.

Blinder, Alan S., 1982, "On Making the Tradeoff between Equality and Efficiency Operational," Chapter 20 in G. R. Feiwel (ed.), Samuelson and Neoclassical Economics, KluwerNijhoff Publishing, Boston MA.

Dalton, Hugh, 1920, "The Measurement of the Inequality of Incomes," The Economic Journal, Vol. 30, No. 119, pp. 348-361.

de V. Graaff, J., 1957, Theoretical Welfare Economics, Cambridge University Press.

Deaton, Angus, 2013, "Measuring Poverty in a Growing World (or Measuring Growth in a Poor World)," Review of Economics and Statistics, Vol. 87, No. 1, pp. 1-19.

Dollar, David, Tatjana Kleineberg, and Aart Kraay, 2015, “Growth, Inequality, and Social Welfare: A Cross-Country Analysis," Economic Policy.

Eden, Maya, 2017, “Is There Enough Redistribution?” World Bank Policy Research Working Paper No. 8003.

Harberger, A. 1983, "Basic Needs versus Distributional Weights in Social Cost-Benefit Analysis," In: Haveman, R., Margolis, J. (Eds.), Public Expenditures and Policy Analysis, $3^{\text {rd }}$ edition, Houghton Miffin, Boston.

Hellebrandt, T., and Mauro, P. 2016. World on the Move: Consumption Patterns in a More Equal Global Economy, Peterson Institute for International Economics.

Hendren, N. 2013. The Policy Elasticity, NBER Working Paper No. 19177 (http://www.nber.org/papers/w19177).

International Monetary Fund, 2017, Inequality and Fiscal Policies, Fiscal Monitor (forthcoming).

Lizarazo, S., A. Peralta-Alva, and D. Puy, 2017, "Macroeconomic and Distributional Effects of Personal Income Tax Reforms: A Heterogenous Agent Model Approach for the U.S." IMF Working Paper, 17/192. 
Okun, Arthur M., 1975, Equality and Efficiency: The Big Tradeoff, Brookings Institution, Washington DC.

Ostry, Jonathan D., Andrew Berg, and Charalambos G. Tsangarides, 2014, "Redistribution, Inequality, and Growth," IMF Staff Discussion Note 14/02.

Pigou, A. C., 1912, Wealth and Welfare, London: Macmillan and co.

Pigou, A. C., 1920, The Economics of Welfare, London: Macmillan and co.

Piketty, Thomas, and Emmanuel Saez, 2013, "Optimal Labor Income Taxation," Chapter 7 in Handbook of Public Economics, Volume 5, Elsevier.

Pirttila, J. and Uusitalo R. 2010. The "Leaky Bucket" in the Real World: Measuring Inequality Aversion using Survey Data. Economica, 77: pp. 60-76.

Sen, Amartya, 1976, “Real National Income,” Review of Economic Studies, Vol. 43, pp. 19-39; reproduced as Chapter 18 in Choice, Welfare, and Measurement, 1982, MIT Press. 